\title{
Modelling the Environmental Effects of Railway Vibrations from Different Types of Rolling Stock: A Numerical Study
}

\author{
Georges Kouroussis, ${ }^{1}$ David P. Connolly, ${ }^{2}$ Konstantinos Vogiatzis, ${ }^{3}$ and Olivier Verlinden ${ }^{1}$ \\ ${ }^{1}$ Faculty of Engineering, Department of Theoretical Mechanics, Dynamics and Vibrations, University of Mons, Place du Parc 20, \\ 7000 Mons, Belgium \\ ${ }^{2}$ Institute for Infrastructure and Environment, School of Energy, Geoscience, Infrastructure \& Society, Heriot-Watt University, \\ Edinburgh EH14 4AS, UK \\ ${ }^{3}$ Laboratory of Transportation Environmental Acoustics (LTEA), School of the Civil Engineering, Transportation Department, \\ University of Thessaly, Pedion Areos, 38334 Volos, Greece
}

Correspondence should be addressed to Georges Kouroussis; georges.kouroussis@umons.ac.be

Received 17 November 2014; Revised 25 January 2015; Accepted 20 February 2015

Academic Editor: Didier Rémond

Copyright (C) 2015 Georges Kouroussis et al. This is an open access article distributed under the Creative Commons Attribution License, which permits unrestricted use, distribution, and reproduction in any medium, provided the original work is properly cited.

This paper analyses the influence of rolling stock dynamics on ground-borne vibration levels. Four vehicle types (Thalys, German ICE, Eurostar, and Belgian freight trains) are investigated using a multibody approach. First, a numerical model is constructed using a flexible track on which the vehicles traverse at constant speed. A two-step approach is used to simulate ground wave propagation which is analysed at various distances from the track. This approach offers a new insight because the train and track are fully coupled. Therefore rail unevenness or other irregularity on the rail/wheel surface can be accurately modelled. Vehicle speed is analysed and the frequency spectrums of track and soil responses are also assessed to investigate different excitation mechanisms, such as carriage periodicities. To efficiently quantify train effects, a new (normalised) metric, defined as the ratio between the peak particle velocity and the nominal axle load, is introduced for a comparison of dynamic excitation. It is concluded that rolling stock dynamics have a significant influence on the free field vibrations at low frequencies, whereas high frequencies are dominated by the presence of track unevenness.

\section{Introduction}

Trains generate ground vibration and noise, which must be addressed during vehicle design in order to reduce its impact. For more than 20 years, theoretical and experimental studies on railway-induced ground vibration have been undertaken, particularly since the widespread development of high-speed rail lines. Furthermore, the interest of scientific and technical communities continues to grow, partially due to recent cases where abnormally high vibration amplitudes were recorded (high-speed lines [1] and metro [2]). As railway ground vibration is a complex problem, it is important to analyse the train excitation and the resulting dynamic excitation mechanisms. There are two main parameters often utilized in prediction modelling [3]: the axle load and the vehicle speed.

The basic mechanisms of ground vibrations are usually described by reducing the vehicle to a sequence of axle loads [4-6] or rigid wheelsets [7]. The axle load is the main parameter that determines the vehicle ground vibration level. It causes track deflection, often termed "static" or "quasistatic," in this case because this mechanism is related to the motion of a static load on an elastically supported beam. Analytical models have been proposed to reduce the vehicle to a set of moving constant loads. Krylov [8] was one of the first authors to propose a track/soil model using Green's functions, where an analytical solution was proposed for predicting the effect of a moving load on an infinite beam resting on a flexible layer. Metrikine and Popp [9] proposed the concept of "equivalent stiffness" representing a onedimensional continuous foundation with complex stiffness to study the steady-state response of an elastic beam on a viscoelastic layer. Similar work has been presented for studying the beam/halfspace interface [10] or the case of embedded tracks [11]. 
Dynamic deflection is caused by the vehicle dynamics and its interaction with the rail through the wheel/rail contacts. In addition to quasistatic deflection, fluctuations can be generated due to wheel/track interaction, which modifies the deflection (dynamic deflection). Random excitation, as proposed by some authors (see, e.g., [12, 13]), addresses this in terms of vehicle/track dynamics, including the effect of vertical track irregularities. In addition, Auersch [14] studied vehicle/track interaction forces by using excitation force spectra. Both vertical rail profile and wheel roundness were analysed, showing that the train speed has a significant influence on vehicle ground vibrations. These prediction models are useful to understand ground wave propagation and refraction, but not best suited to analyse the effect of the parameters of a railway vehicle (suspension, sprung, unsprung masses, etc.) on the vibration levels.

The effect of vehicle speed on railway-induced ground vibrations has been thoroughly documented. It is well known that an increase of vehicle speed generally results in an increase of ground vibration level. Particularly, when the vehicle reaches the so-called soil critical speed (which corresponds to the Rayleigh wave velocity $c_{R}$ of the soil) a resonance-like phenomenon is observed for the track and the soil [15-17], which considerably increases the ground vibration. This observation can be made in railway lines on soft soil but it is not common in practice, given that soft soils, with $c_{R}<80 \mathrm{~m} / \mathrm{s}(\approx 300 \mathrm{~km} / \mathrm{h}$-maximum commercial speed for high-speed train), are rare. Sheng et al. [18] point out that where the vehicle travels below this critical speed, the dynamic mechanism of vibration generation is considerably more important than contribution of the quasistatic axle loads.

As the source of vibration is the wheel/rail contact, it is useful to study the vehicle interaction with the track and the soil. Galvín et al. [19] proposed a detailed vehicle model using lumped masses coupled to a three-dimensional track/soil finite element and boundary element analysis in order to consider the quasistatic and the dynamic excitation mechanisms. Lombaert et al. [20] used a statistical procedure to quantify the characterization of the track unevenness and its variability in ground vibration predictions. Auersch and Said [21] demonstrated, by comparing several excitation sources (road and rail traffic, vibratory construction work, explosions, etc.), that the attenuation of ground vibrations with increasing distance $d$ strongly depends on the source. For railway vibrations, this was corroborated by Connolly et al. [22]. Furthermore, Costa et al. [23] have shown the importance of integrating a multibody model of the vehicle in the track/soil simulation and it was shown that the sprung masses have minimal effects on the ground vibration motion. Kouroussis et al. [24] also analysed vehicle contributions in the case of local defects (i.e., stepwise shape). Without introducing countermeasures in the track or in the soil, it is possible to reduce the energy transmitted from the track to the ground (up to 70\%) by modifying the mechanical characteristics of the train. Despite this, vehicle configuration has not been thoroughly observed for cases of distributed overall roughness, except for in a recent study [25]. Additional and similar studies are described in [26].
The present contribution focuses on the vehicle vertical dynamics and their influence on the railway-induced ground vibrations. A section describing the adopted prediction model is included. Utilizing the proposed method, four vehicle types (based on commercial trains) are included in the study. Vehicle model analysis, wheel impedance calculation, and track deflection studies are performed in order to emphasize the main contribution to the ground vibration. The latter is predicted through the finite/infinite element approach. Free field vibrations are analysed by comparing the time domain indicators and frequency content. A detailed comparison is made into the ratio between the peak particle velocity and the axle load, for various distances from the track, and the vehicle speed effect on ground vibration level. The main objective is to analyse rolling stock and the parameters which influence the characteristics of the ground vibration.

\section{Modelling Approach}

In [27] the authors present a validated prediction model working in two stages, taking into account the vehicle dynamics influence on track deflection and therefore on ground wave propagation (Figure 1). More recently, a new kind of foundation specially dedicated to the track modelling has been developed in [28], for filling the gap in track/soil decoupling. The following presents some elements about the modelling.

2.1. Vehicle Modelling. To model the vehicle behaviour, multibody codes are commonly used by train constructors and designers. The approach used by these codes is to assemble classical elements like bodies (either rigid or flexible) and joints and force elements to build the model of the mechanical system. Thereby the wheel/rail contact, which is the source of the forces exciting the vehicle, requires complex modelling. Primary and secondary suspensions are designed in order to place the bogie and car body rigid modes under 10$15 \mathrm{~Hz}$. This constraint implies a dynamic load reduction in the wheel-rail interface. At low frequencies, the rail flexibility is assumed to be constant. Many standards for vibration [29-31] assume that low frequency vibrations have the most critical effect on buildings and on human exposure. For this reason it is preferable to include vehicle simulation in ground vibration modelling. For the proposed model, a "minimal coordinates" approach is adopted to generate the equations of motion, thereby generating condensed codes [32].

The system includes a vehicle model defined using a multibody formalism, though any model could be represented in this manner. A $2 \mathrm{D}$ approach is preferred, considering only the bounce motion of the car bodies and the wheelsets and the bounce and pitch motions of the bogies. As all bodies of the vehicle model move with a constant driving velocity along the track, the longitudinal motion is assumed to be known a priori and does not need to be involved in the model. Moreover, small pitch angles can be assumed so that the governing equations of the vehicle model are reduced to their linearised form:

$$
\left[\mathbf{M}_{v}\right]\left\{\underline{\ddot{\mathbf{q}}}_{v}\right\}+\left[\mathbf{C}_{v}\right]\left\{\underline{\dot{\mathbf{q}}}_{v}\right\}+\left[\mathbf{K}_{v}\right]\left\{\underline{\mathbf{q}}_{v}\right\}=\left\{\underline{\mathbf{f}}_{v}\right\} .
$$




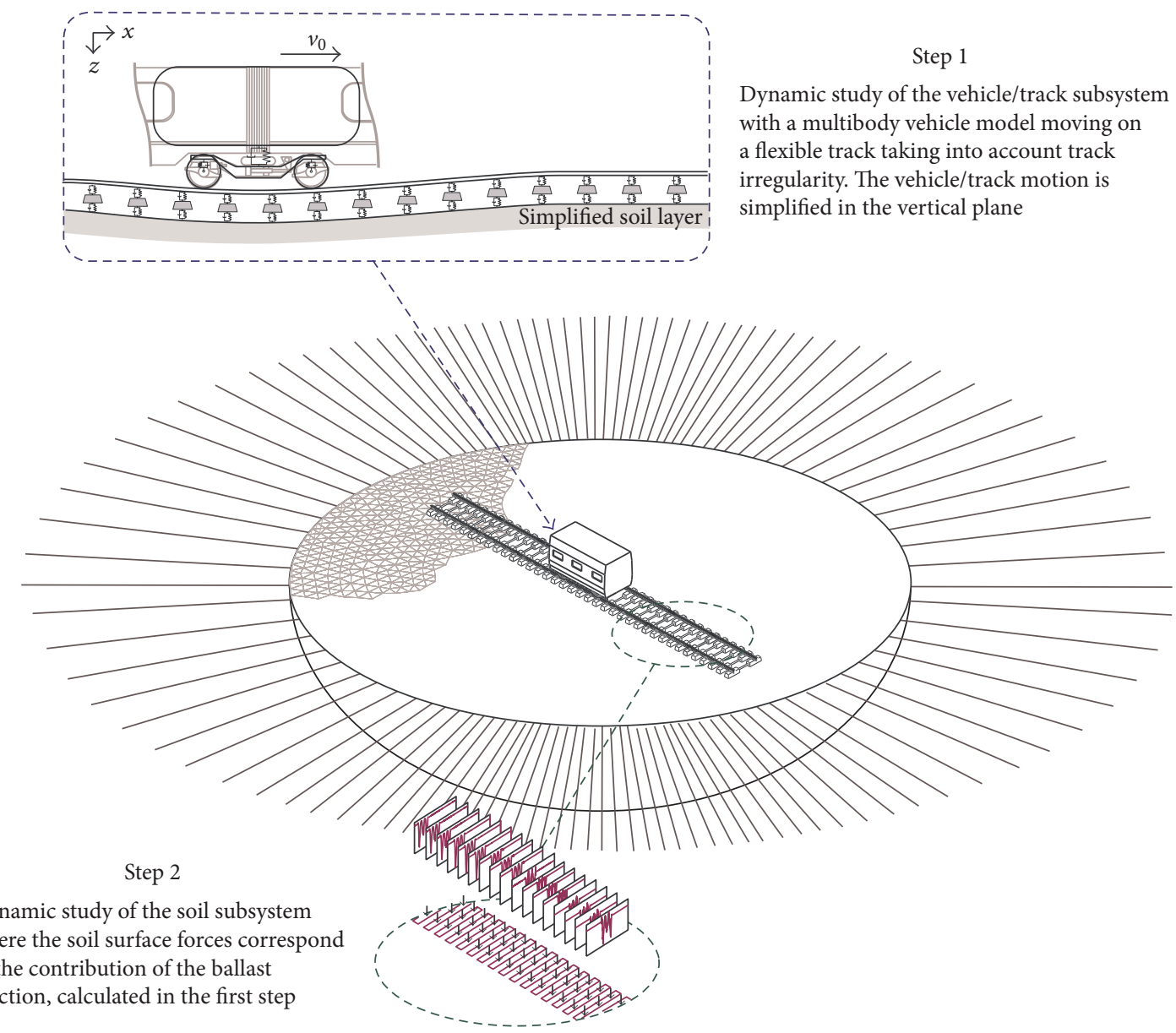

FIGURE 1: Vehicle/track/soil model, working in two steps.

The kinematics of this system are described by the configuration parameters $\underline{\mathbf{q}}_{v}$ of the vehicle. Vector $\underline{\mathbf{f}}_{v}$ includes the gravitational forces acting on each body and the wheel/rail contact forces. The gravitational forces are responsible for static deflection of the track. Dynamic deflection is imposed by the interaction between the vehicle and the track.

2.2. Track Modelling. A three-layer model (rail - railpad sleeper - ballast - foundation) represents the vertical track behaviour. The rail is modelled by a Euler-Bernoulli beam, discretely supported by the sleepers. The degrees of freedom of the vehicle are in the same plane as the track. The flexible rail, defined by its Young modulus $E_{r}$, its geometrical moment of inertia $I_{r}$, its section $A_{r}$, and its density $\rho_{r}$, is described by the finite element method ( $N$ elements). A regular spacing $L$ of the sleepers has been considered, with a discretization of $N_{n}$ elements for one sleeper spacing. The number of track configuration parameters is equal to $2 \mathrm{~N}+$ 2 (rail) plus $2 N / N_{n}+2$ (subgrade). Viscoelastic properties are considered for the railpads and ballast, characterised by springs and dampers $\left(k_{p}\right.$ and $d_{p}$ for the railpad, $k_{b}$ and $d_{b}$ for the ballast). The sleepers have a lumped mass $m$. The foundation is defined by a coupled lumped mass model [28], as presented in Figure 2 . The parameters $m_{f}, k_{f}, k_{c}, d_{f}$, and $d_{c}$, simultaneously take into account the inertial, stiffness, and kinematic interaction of direct and adjacent foundations where the track lies. The forces exerted by the wheels on the rail are calculated from the wheel/rail contact, thus coupling the vehicle and track.

The chosen model for the track considers rigid sleepers and Euler-Bernoulli beams for the rail. Models using Timoshenko formulation for the rail masses are less common because, for ground-borne vibration modelling (e.g., $<100 \mathrm{~Hz}$ ), they do not provide significant benefit $[33,34]$. In addition, numerical track defection results using a EulerBernoulli approach have been validated using the analytical solution proposed in [8] (detailed results are presented in [27]).

2.3. Wheel/Rail Contact. The vertical wheel/rail contact forces are calculated according to Hertzian theory. The dynamic forces generated by the contact area and acting on each wheel $i$ and on the rail at the coordinate $x_{j}$ can be written as follows:

$$
F_{\text {rail } / \text { wheel }, i}=\left\{\begin{aligned}
&-K_{\mathrm{Hz}}\left(z_{w, i}-z_{r}\left(x_{j}\right)-h\left(x_{j}\right)\right)^{3 / 2} \\
& \text { if } z_{w, i}>\left(z_{r}\left(x_{j}\right)-h\left(x_{j}\right)\right) \\
& 0 \quad \text { otherwise }
\end{aligned}\right.
$$




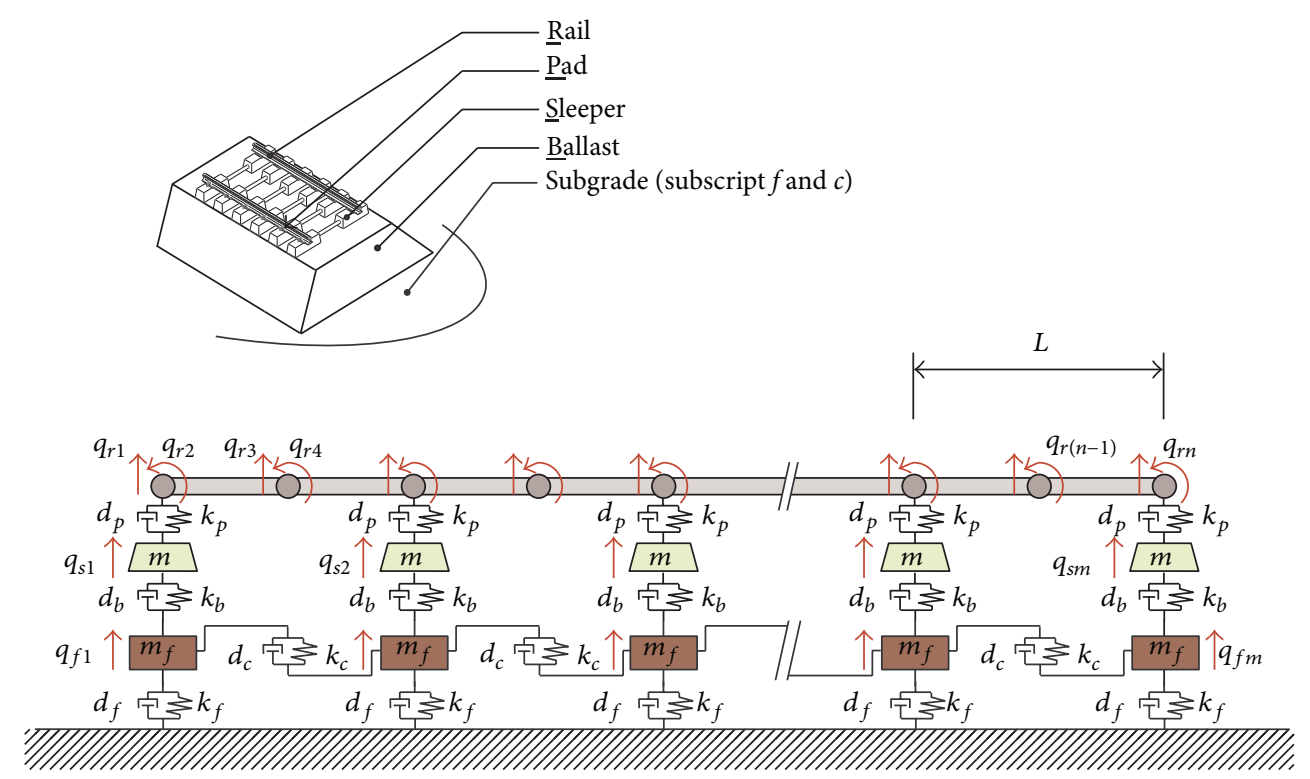

Figure 2: Dynamic model of the track, including the foundation.

where $z_{w, i}$ denotes the vertical displacement of the $i$ th wheelset; $z_{r}\left(x_{j}\right)$ denotes the vertical displacement of the rail at contact point; and $K_{\mathrm{Hz}}$ is the Hertzian coefficient. The function $h(x)$ represents defects on the rail surface. In the model, it is defined with the help of power spectral density functions proposed by Garg and Dukkipati [35]. One has

$$
H(\phi)=\frac{A \phi_{2}^{2}\left(\phi^{2}+\phi_{1}^{2}\right)}{\phi^{4}\left(\phi^{2}+\phi_{2}^{2}\right)} .
$$

In the present analysis, a medium class quality is the representative source of vibrations. Vibration levels may be sufficiently amplified assuming a degraded rail profile, in contrast to an ideal surface rail. The roughness constant $A$ is therefore equal to $0.53 \mu \mathrm{m}$, and the two cut-off spatial frequencies $\phi_{1}=23.3 \times 10^{-3} \mathrm{~m}^{-1}$ and $\phi_{2}=13.1 \times 10^{-2} \mathrm{~m}^{-1}$. In the time domain simulation, a quasistochastic generation process is performed from the spacial frequency $\phi$ to the spatial domain $x$ according to the following Fourier series:

$$
h(x)=\sum_{k} \sqrt{2 \Delta \phi H(k \Delta \phi)} \cos \left(k \Delta \phi x+\varphi_{k}\right),
$$

where $\Delta \phi$ is the spatial frequency resolution and the phase $\varphi_{k}$ is determined randomly according to a uniform distribution between 0 and $2 \pi$. This representation was selected for a wavelength range from 0.1 to $10 \mathrm{~m}$ [24], which corresponds to a dynamic excitation between 4 and around $400 \mathrm{~Hz}$ for a vehicle speed of $150 \mathrm{~km} / \mathrm{h}$ (between 3 and $\approx 300 \mathrm{~Hz}$ for a speed of $100 \mathrm{~km} / \mathrm{h}$ ). This proposed track irregularity class provides an effective value of irregularity comprised at $\pm 250 \mu \mathrm{m}$ with a variance of $27.37 \times 10^{-4} \mathrm{~m}^{2}$. This corresponds to a medium class rail vertical profile.

The simulation of the vehicle/track subsystem is performed in the time domain, taking into account the nonlinear contact law (2). A Newmark integration scheme is used to integrate the equations of the vehicle and the track, with the help of the home-made EasyDyn [36] library, which simulates problems represented by second-order differential equations and, more particularly, multibody systems. Considering a complete vehicle, its length can be greater than the length of the flexible track model so a rigid track is added on both sides of the finite element model track model. Between the rigid and flexible track parts, a transition area is defined, with gradually increasing flexibility [27]. Before the simulation, a static equilibrium is performed for the whole vehicle/track subsystem, in order to determine of the static equilibrium position of each vehicle body and of the flexible track.

2.4. Soil Modelling. The first step of the model gives the vehicle/track motion and also the ballast reaction forces $\underline{\mathbf{f}}_{\text {soil }}$, which represent the forces acting at the soil surface. One has

$$
\left\{\underline{\mathbf{f}}_{\text {soil }}\right\}=\left[\mathbf{C}_{b}\right]\left(\left\{\underline{\dot{\mathbf{q}}}_{f}\right\}-\left\{\underline{\dot{\mathbf{q}}}_{s}\right\}\right)+\left[\mathbf{K}_{b}\right]\left(\left\{\underline{\mathbf{q}}_{f}\right\}-\left\{\underline{\mathbf{q}}_{s}\right\}\right),
$$

where $\mathbf{C}_{b}$ and $\mathbf{K}_{b}$ represent damping and stiffness matrices related to ballast behaviour in the track model, and subscripts $s$ and $f$ are related to the sleepers and foundation dofs, respectively.

In the second subproblem, the free field response is computed from these forces (Figure 3). The soil is represented by a finite element model, surrounded by viscous boundaries and infinite elements, representing an efficient nonreflecting border mimicking infinity [37]. A validation of the time response approach with respect to analytical solutions can be found in [38]. A linear behaviour is assumed for this medium (Young's modulus $E$, density $\rho$, Poisson ratio $\nu$, and viscous damping $\beta$ ). An implicit scheme is often used for this type 


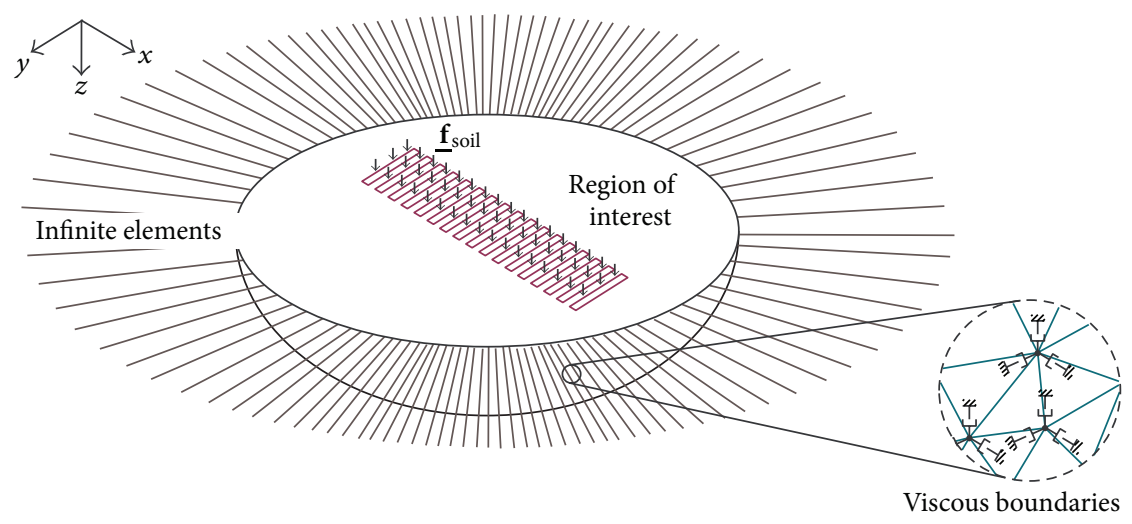

Figure 3: The finite/infinite element model for the soil.

of problem; however computing requirements (memory and CPU-time) limit its use. In comparison, using an explicit scheme helps to reduce calculation time. Instead of the Newmark integration scheme chosen to solve the equations of motion for the vehicle/track subsystem, the equations of motion describing the soil dynamics are integrated using an explicit central difference integration rule. Various analyses have been performed to verify that the results yielded by the explicit integration are very close to their implicit equivalent. The decreased calculation time is significant, with more than a $70 \%$ reduction [37]. In addition, it should be noted that a safeguard is incorporated through comparison of the kinetic energy history and the total internal energy. The ratio of these two energies must be lower than a limit value defined by the analysis type [39].

\section{Studied Vehicles}

Four vehicles are studied in the present analysis, with their own characteristics (Figure 4 and Table 1).

(i) The Thalys high-speed train (HST) is derived from the French TGV. It operates between Paris, Brussels, Köln, and Amsterdam (also called PBKA train). It consists of two locomotives and eight carriages, with a total length of $200 \mathrm{~m}$. The two locomotives are supported by two bogies. Instead of the conventional bogie configuration of two-to-a-car, Jacobs bogies are used for the carriage bogies, with the exception of the side carriage bogies near the power car and at the middle of the vehicle. All the bogies present a wheelset spacing of $3 \mathrm{~m}$.

(ii) Also known as the TransManche Super Train (CrossChannel Super Train), the Eurostar train is the longest HST, with a length of $394 \mathrm{~m}$, and the faster train in regular UK passenger service. Its geometrical and inertia characteristics are very similar to the Thalys, except in the middle of the train (specialised trainsets are used in the center for safety reasons).

(iii) The German InterCity train is also studied. The typical trainset contains 8 cars, with a classical bogie configuration. The trainset consists of 2 power cars and 6 intermediate cars. Contrary to the preceding trains, the bogie axle spacing is only $2.5 \mathrm{~m}$.

(iv) The last vehicle is a Belgian freight train which has a large mass and with stiff primary suspensions (193 kN/wheelset-40\% more than the Thalys and Eurostar loading and more than twice as much the ICE). Although the locomotive presents a bogie axle spacing of $3.0 \mathrm{~m}$, the carriage bogies have a spacing of $2.5 \mathrm{~m}$.

The vehicles are modelled in the following way.

(i) The bogie frame is composed of a rigid body (mass $m_{b}$, moment of inertia $I_{b}$ ) connected to a mass $m_{c}$, representing a half car body, through the secondary suspension $\left(k_{2}, d_{2}\right)$. Each wheelset of mass $m_{w}$ is linked to the bogie with a spring/damper system $\left(k_{1}\right.$, $d_{1}$ ) defining the primary suspension.

(ii) All the bogies move at constant speed $v_{0}$. For simplicity in comparing results, each bogie of a given vehicle presents the same dynamics characteristics and therefore the same axle load (Table 1). The values are based on a mean of all carriages.

Table 2 summarizes the main vibration modes of each vehicle, with the corresponding natural frequencies $f_{0, i}$ and damping ratios $\xi_{i}$ calculated for each mode considering the coupling of the vehicle with the track (a linearised version of Hertz's contact is used in this case). Car body bounce modes are around $1 \mathrm{~Hz}$ for all the vehicles. Considering the bogie modes (bounce and pitch motions), the first three vehicles present similar undamped natural frequencies, with damping ratios varying from $9 \%$ to $104 \%$ (particularity of the ICE train bogie pitch mode). The freight train presents high bogie mode frequencies, common for this kind of vehicle. Finally, axle hop modes, around $70 \mathrm{~Hz}$, are clearly independent of the train type and are strongly damped.

Complementary to this analysis, frequency response functions of the car body and bogie are given in Figure 5, when an excitation is applied on the front wheel of the first bogie, showing the importance of these modes. ICE (Figure 5(c)) and Thalys (Figure 5(a)) trains present the same behaviour. The Eurostar HST curve reveals that the first mode 


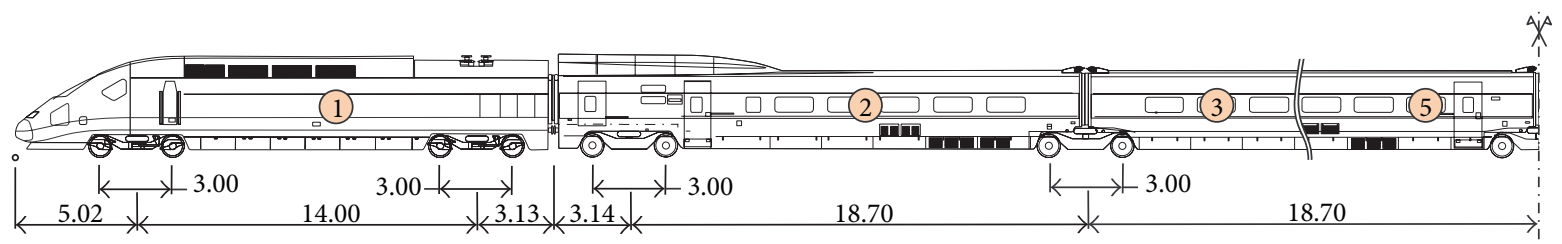

(a) Thalys HST (Alstom): 10-car configuration

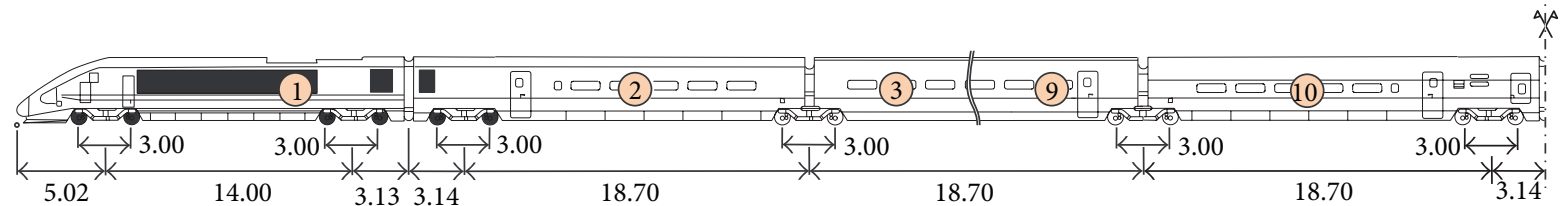

(b) Eurostar HST (Alstom): 20-car configuration

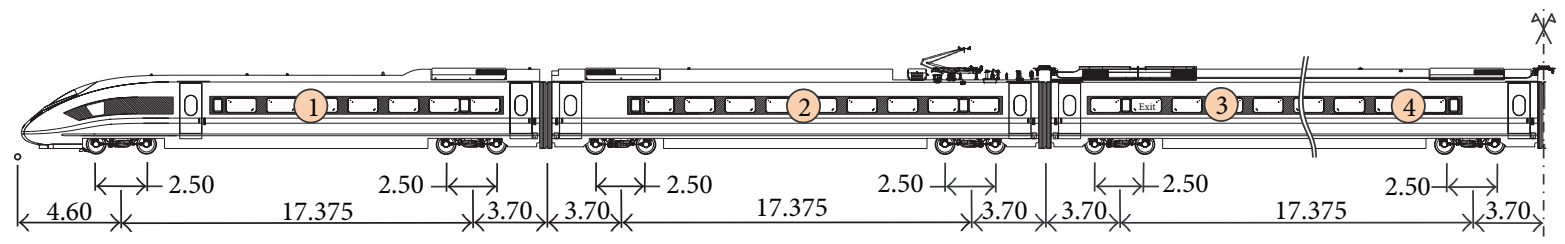

(c) ICE train (Siemens): 8-car configuration

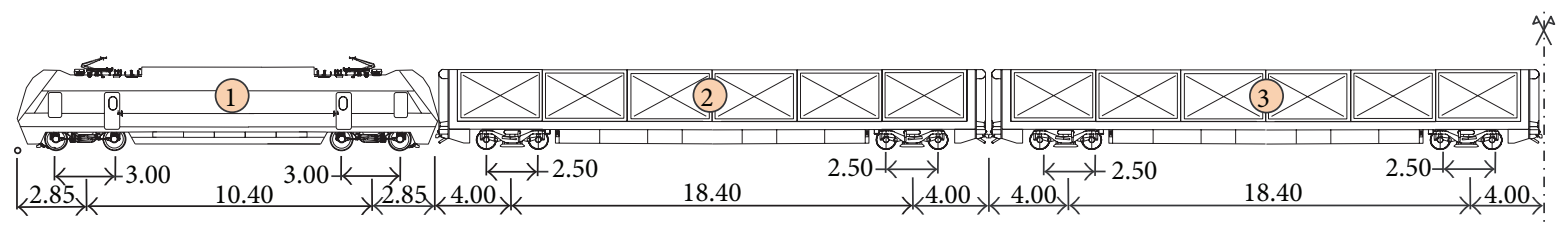

(d) Freight train: 6-car configuration

FIGURE 4: Geometrical configurations of the studied vehicles.

TABLE 1: Dynamic parameters of the studied trains.

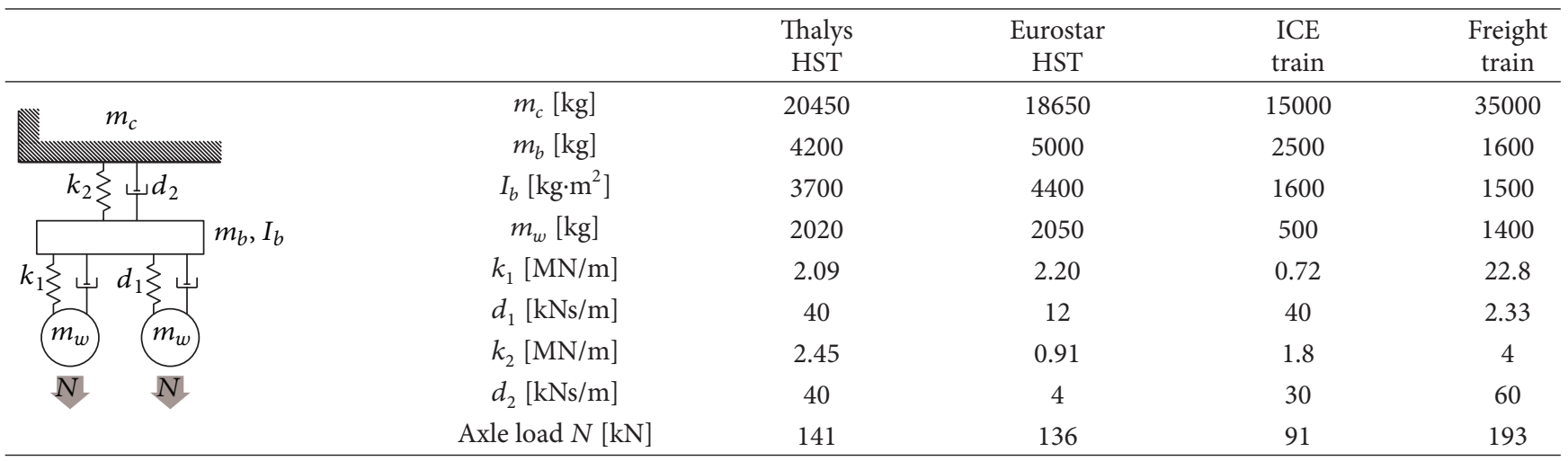

(car body-on-suspension) and the second modes are less damped, compared to the Thalys HST curves (Figure 5(b)). The bogie receptance related to the freight train is dominated by a bogie bounce mode at $27.8 \mathrm{~Hz}$ (Figure 5(d)). Bogie pitch and axle hop modes do not influence these receptances. These curves already emphasize significant differences between the studied vehicles.

An interesting and simple approach for understanding the dynamic behaviour of the vehicle/track system considers wheel receptance, displayed in Figure 6 in the frequency range $0-100 \mathrm{~Hz}$. These receptances also include the contribution of the track, such that the presented curves reflect the total receptance experienced by the wheel. An overall decrease is observed with the frequency. Some variations are observed in the vehicle modes, although this is not true for all cases. For example, the bogie pitch mode of the freight train at $34.4 \mathrm{~Hz}$ is easily identifiable. Notice that these curves are calculated using a track coupled formulation. An accurate knowledge of wheel receptances is crucial to understand the wheel/rail interaction and its magnitude. 
TABle 2: Mode shapes of the studied trains (coupled with the track).

ICE train
Thalys HST

\section{Track Deflection}

Several mechanisms are identified as sources of ground transmitted vibrations. The wheel/axle weight is transmitted to the ground through the sleepers and is modulated by the vehicle and track periodicity. In addition to axle loads, the track irregularity intensifies ground forces. Some of these can be directly observable in the track deflection. For a vehicle speed $v_{0}$, different passage excitation mechanisms can be defined as

(i) the fundamental axle passage frequency:

$$
f_{a}=\frac{v_{0}}{L_{a}}
$$

(ii) the fundamental bogie passage frequency:

$$
f_{b}=\frac{v_{0}}{L_{b}}
$$

(iii) the fundamental carriage passage frequency:

$$
f_{c}=\frac{v_{0}}{L_{c}}
$$

(iv) the sleeper passage frequency:

$$
f_{s}=\frac{v_{0}}{L},
$$

where the various lengths $L_{i}$ are illustrated in Figure 7. These mechanisms are coupled to the track/soil reaction.

The numerical results are based on track and soil configurations of a site in Belgium near Mévergnies (a town near the
TABle 3: Parameters of the track at Mévergnies (Belgium).

\begin{tabular}{lcccc}
\hline$E_{r}$ & $I_{r}$ & $\rho_{r}$ & $A_{r}$ & $d$ \\
\hline $210 \mathrm{GPa}$ & $3055 \mathrm{~cm}^{4}$ & $7850 \mathrm{~kg} / \mathrm{m}^{3}$ & $76.9 \mathrm{~cm}^{2}$ & $0.6 \mathrm{~m}$ \\
\hline$k_{p}$ & $d_{p}$ & $k_{b}$ & $d_{b}$ & $m$ \\
\hline $120 \mathrm{MN} / \mathrm{m}$ & $4 \mathrm{kNs} / \mathrm{m}$ & $47 \mathrm{MN} / \mathrm{m}$ & $72 \mathrm{kNs} / \mathrm{m}$ & $150 \mathrm{~kg}$ \\
\hline
\end{tabular}

TABLE 4: Mévergnies site (Belgium)_half-space configuration.

\begin{tabular}{lccccc}
\hline$E$ & $\rho$ & $v$ & $c_{P}$ & $c_{S}$ & $\beta$ \\
\hline $129 \mathrm{MPa}$ & $1600 \mathrm{~kg} / \mathrm{m}^{3}$ & 0.3 & $330 \mathrm{~m} / \mathrm{s}$ & $177 \mathrm{~m} / \mathrm{s}$ & $0.0004 \mathrm{~s}$ \\
\hline$m_{f}$ & $d_{f}$ & $k_{f}$ & $d_{c}$ & $k_{c}$ \\
\hline $380 \mathrm{~kg}$ & $680 \mathrm{kNs} / \mathrm{m}$ & $72 \mathrm{MN} / \mathrm{m}$ & $-155 \mathrm{kNs} / \mathrm{m}$ & $160 \mathrm{MN} / \mathrm{m}$ \\
\hline
\end{tabular}

French border of Belgium that the high-speed west line L1 crosses) where in situ measurements have been performed in the past. Tables 3 and 4 summarize the dynamic parameters of the track and soil, respectively. A homogeneous configuration is assumed for the soil, allowing for a standardised comparison of the final results (this configuration avoids additional vibration frequencies due to soil layer resonances). Table 4 also provides the ground body wave speeds $c_{P}$ and $c_{S}$, derived from soil elasticity parameters.

Figure 8 presents the frequency content of the rail deflection simulated for each rolling stock and for a speed of $150 \mathrm{~km} / \mathrm{h}$. Supplementary results (called "moving axle load") are shown on the curve, representing the equivalent results with constant axle loads for vehicle excitation. Compared to the classical multibody approach chosen for the vehicle, the moving axle load model takes into account loaded wheelsets for the vehicle, without the vehicle dynamic characteristics. Therefore these ignore track irregularities and vehicle 


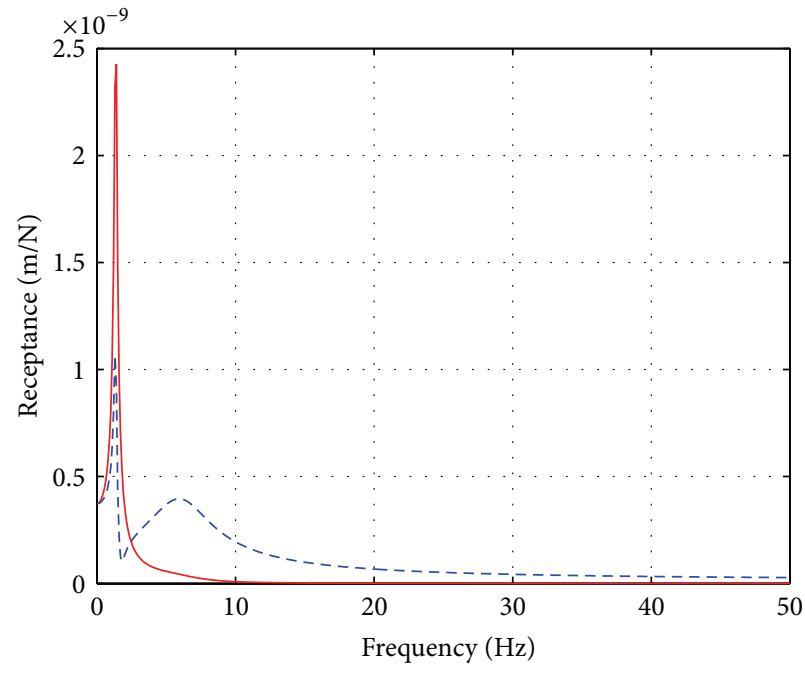

(a) Thalys HST

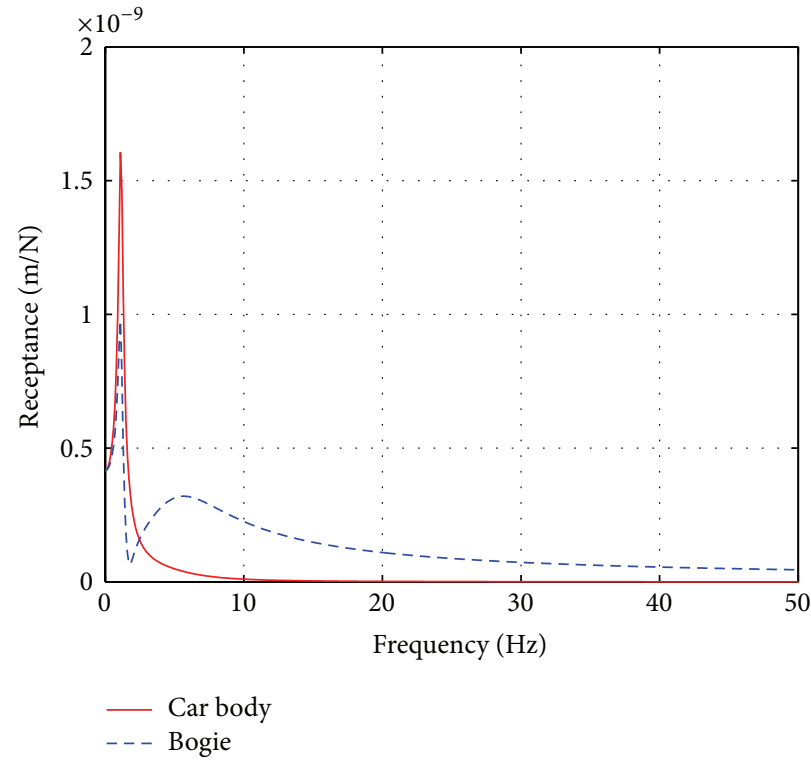

(c) ICE train

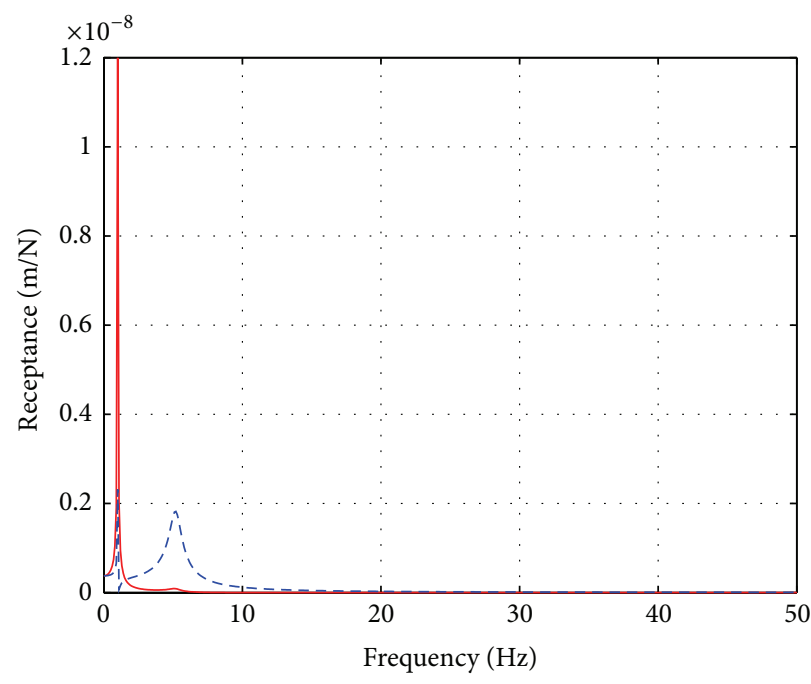

(b) Eurostar HST

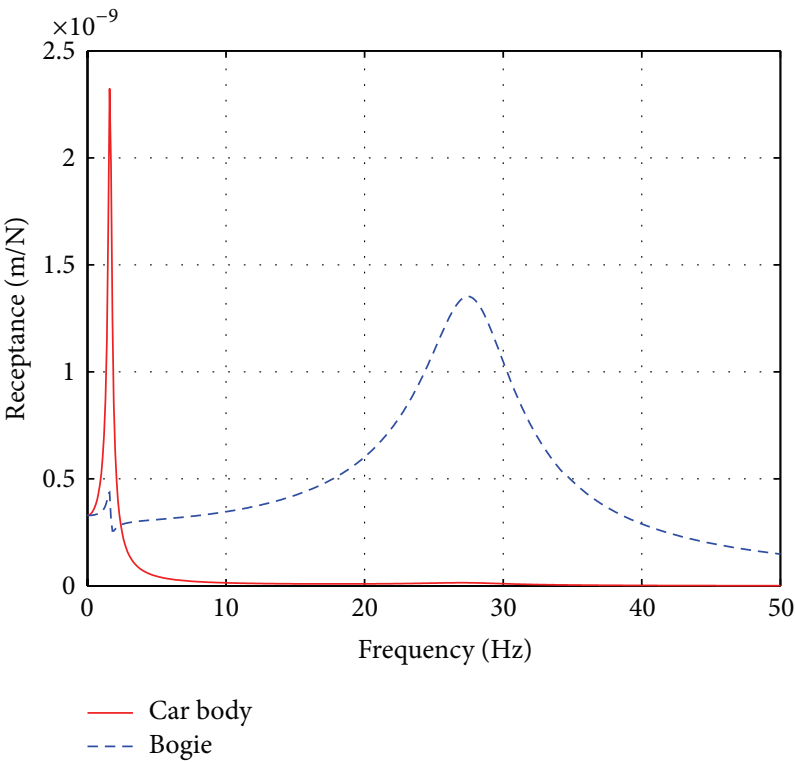

(d) Freight train

Figure 5: Frequency response functions of the studied trains (vertical excitation at front wheel and vertical displacements of car body and bogie).

dynamic interaction with the track/foundation system. They allow comparison of the effect of vehicle dynamics directly on rail deflection. The excitation passage spectrum is also added for each vehicle, comparing the track deflection frequency content with the train excitation mechanisms. The following observations are noteworthy.

(i) Results related to the axle load configuration are close to those based on a multibody vehicle model. Some discrepancies exist at low and high frequencies but they appear, at first glance, as negligible. Notice that the freight train presents a small decrease in track deflection magnitude for the multibody model compared to the constant axle load model. (ii) The frequency content is significant up to around $30 \mathrm{~Hz}$. Some peaks emerge from the spectra and are related to the passage excitation mechanisms but the type depends on the vehicle configuration. For example, Eurostar and Thalys HST present the same bogie and carriage passage frequencies $f_{b}$ and $f_{c}$ (with the exception of the two locomotives) and the corresponding curves (Figures $8(\mathrm{a})$ and $8(\mathrm{~b})$ ) are dominated by the fundamental (around $2.2 \mathrm{~Hz}$ ) and harmonic frequencies. The carriage passage frequency $f_{c}$ is around $1.6 \mathrm{~Hz}$ for ICE and freight trains and is different to the bogie passage frequency $f_{b}\left(f_{b}=\right.$ $2.4 \mathrm{~Hz}$ and $f_{c}=1.7 \mathrm{~Hz}$ for the ICE train). This can be observed in Figures 8(c) and 8(d). An amplitude modulation is also observable, due to the fundamental axle 


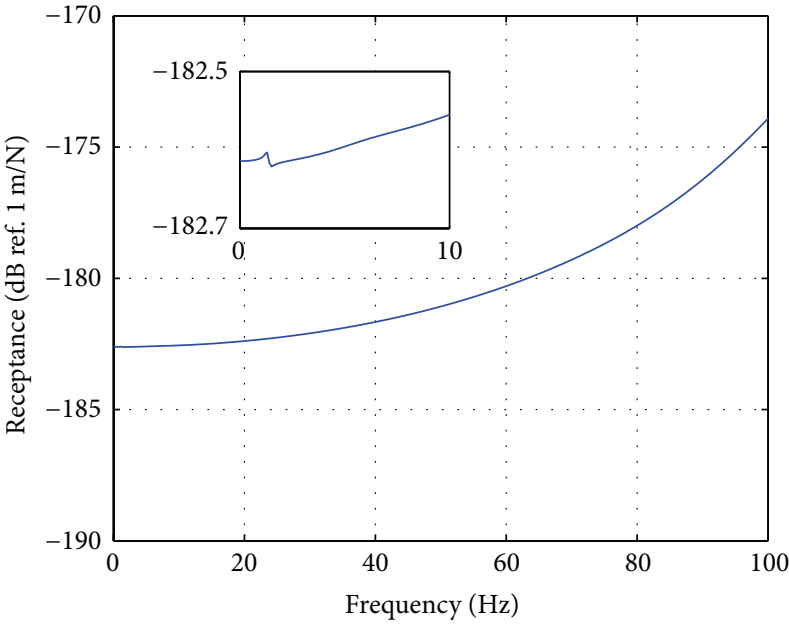

(a) Thalys HST

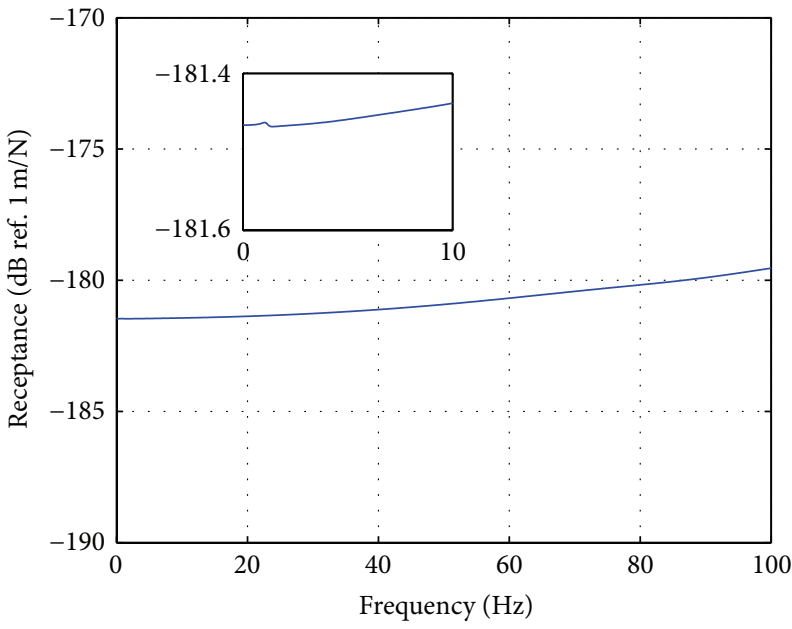

(c) ICE train

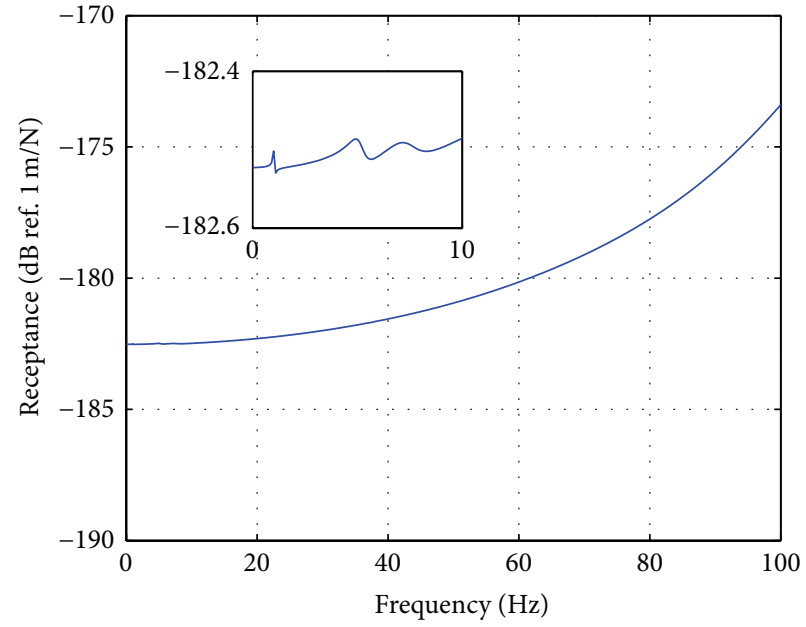

(b) Eurostar HST

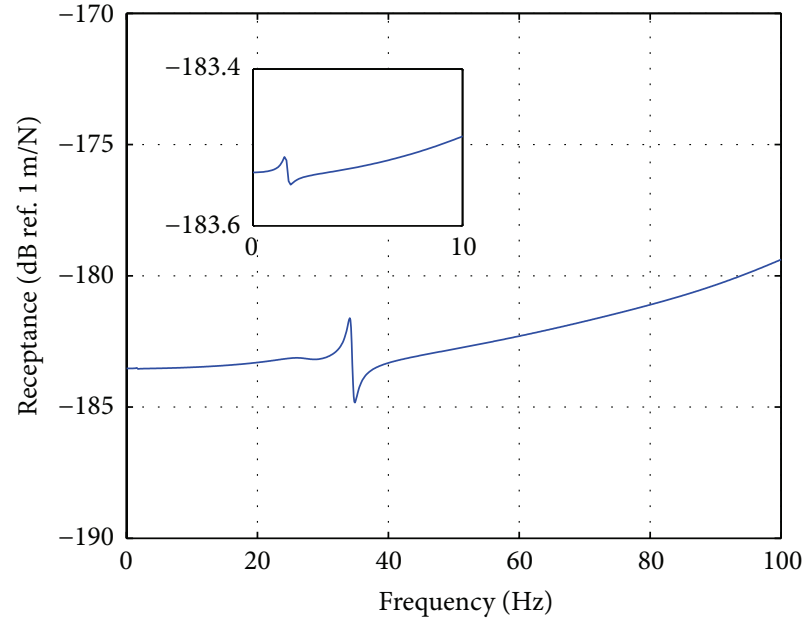

(d) Freight train

FIGURE 6: Spectral content of the first wheel receptances (calculated for a position of the wheel at midspan of sleepers).

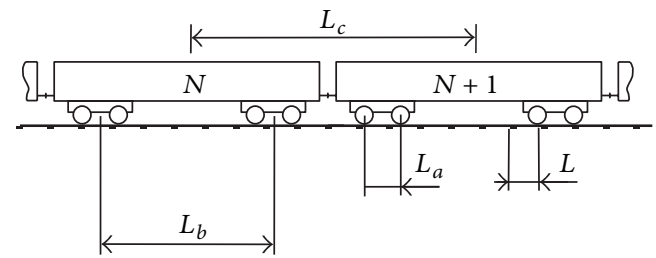

FIGURE 7: Rudimentary geometrical parameters of the train and the track.

passage frequency $f_{a}$, provided by (6), at relatively higher frequencies (at $13.9 \mathrm{~Hz}$ or $16.7 \mathrm{~Hz}$ depending on the vehicle type). This phenomenon modifies the magnitude of the carriage passage frequencies and determines the amplitude spectra envelope (e.g., fifth harmonic carriage frequency at $8 \mathrm{~Hz}$ is completely suppressed for the ICE train results). The locomotive excitations are different from the carriages and do not clearly appear in the frequency curves. (iii) The sleeper passage frequency is not observable on the results, since it does not contribute to track deflection. This statement has been recently proved by comparing track deflections for discrete and continuous supports [27].

(iv) The importance of each peak also depends on the geometrical and dynamic configuration of the vehicle. For example, the Eurostar and freight train present dominant eigenfrequencies at around $2 \mathrm{~Hz}$ and $5 \mathrm{~Hz}$, respectively. Thalys and Eurostar HTS graphs are identical at high frequencies.

\section{Free Field Ground Vibrations}

Considering ground surface motion, the simulation has been performed using the data in Table 4. Figure 9 presents each time history of the vertical velocity $v_{z}(t)$ at ground surface, located at $10 \mathrm{~m}$ from the track and for a vehicle speed of $150 \mathrm{~km} / \mathrm{h}$. Each result has a different time duration, 

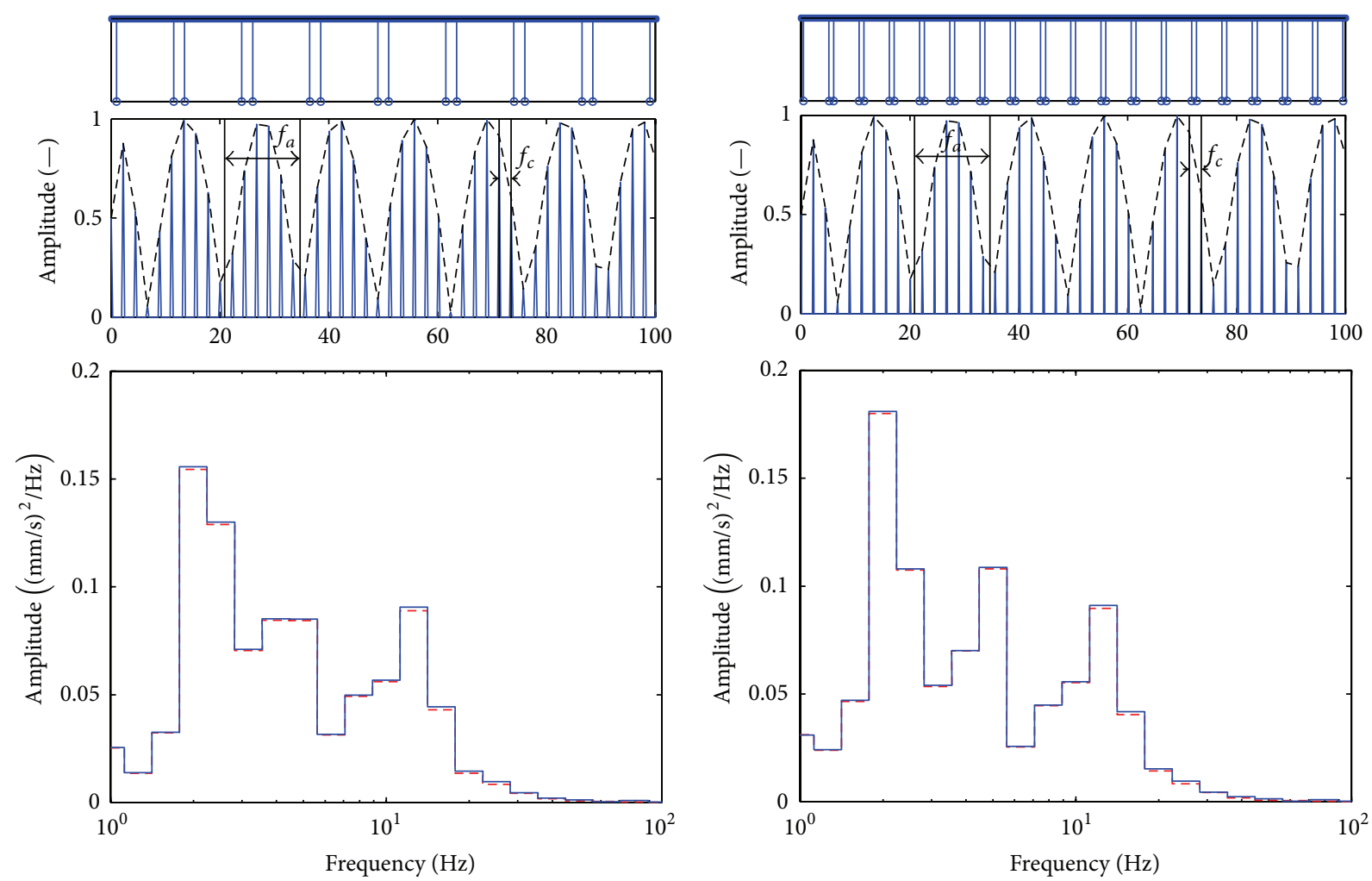

(a) Thalys HST

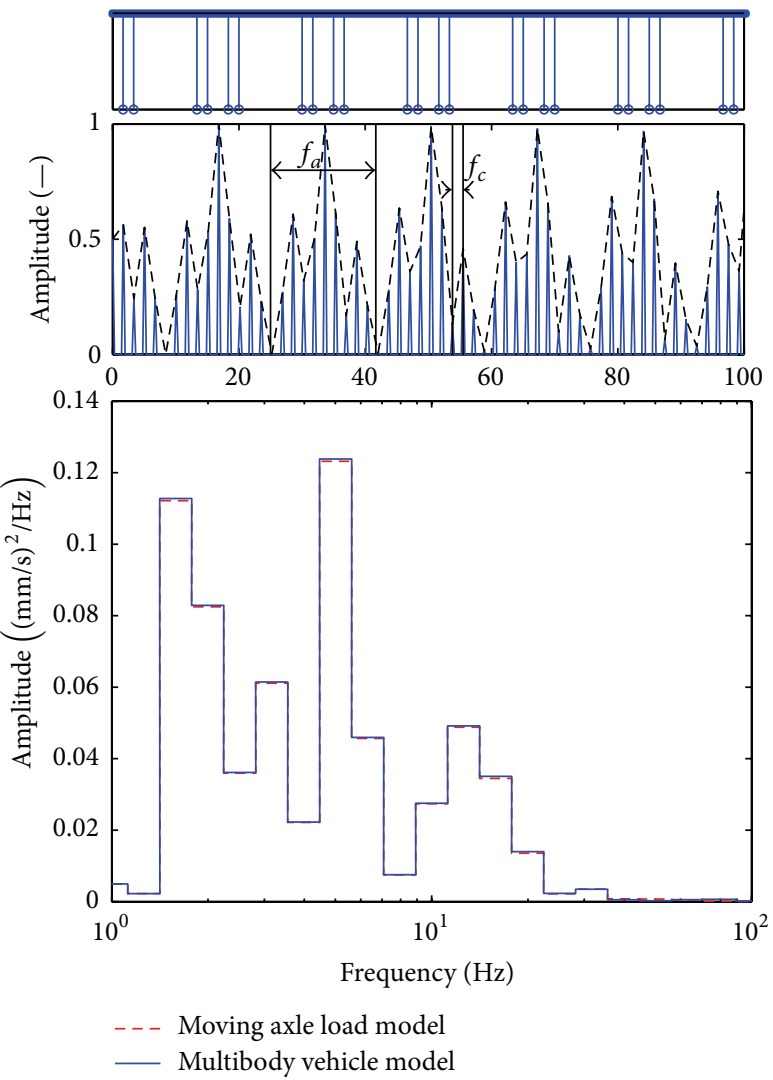

(c) ICE train

(b) Eurostar HST
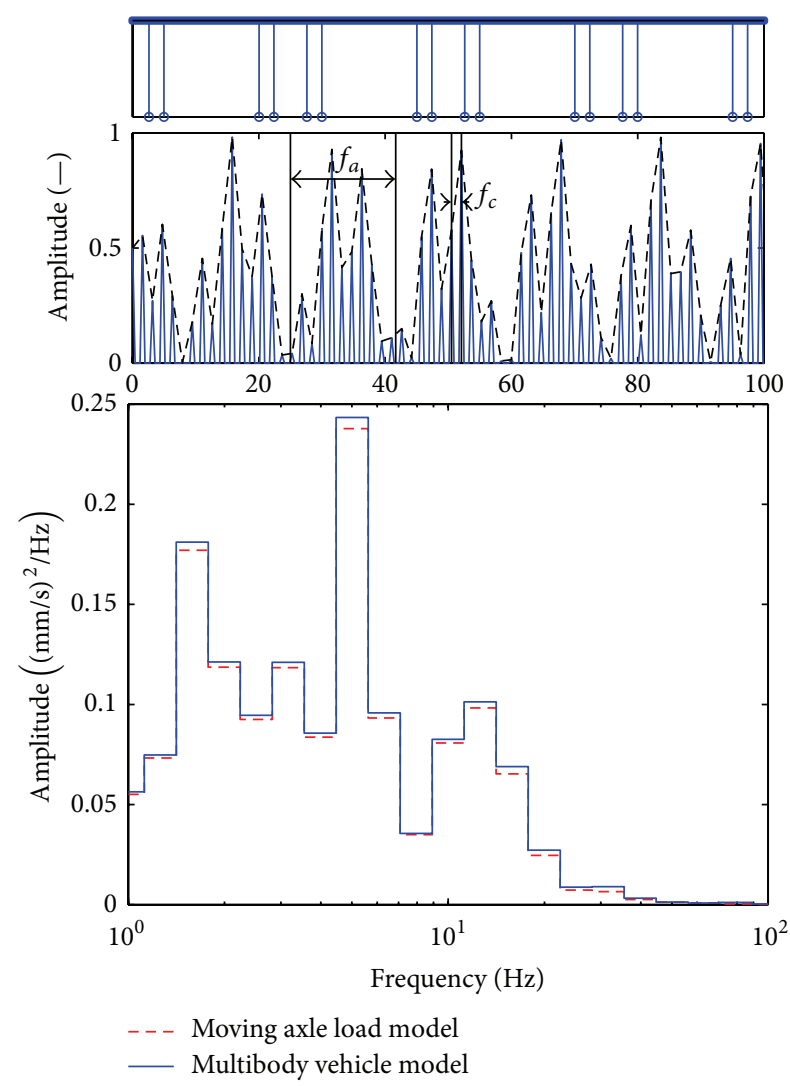

(d) Freight train

FIGURE 8: Frequency content of the vertical track deflection, as a function of the studied trains at speed $v_{0}=150 \mathrm{~km} / \mathrm{h}$ (for each subfigure, top: train passage excitation; bottom: one-third octave band spectra). 


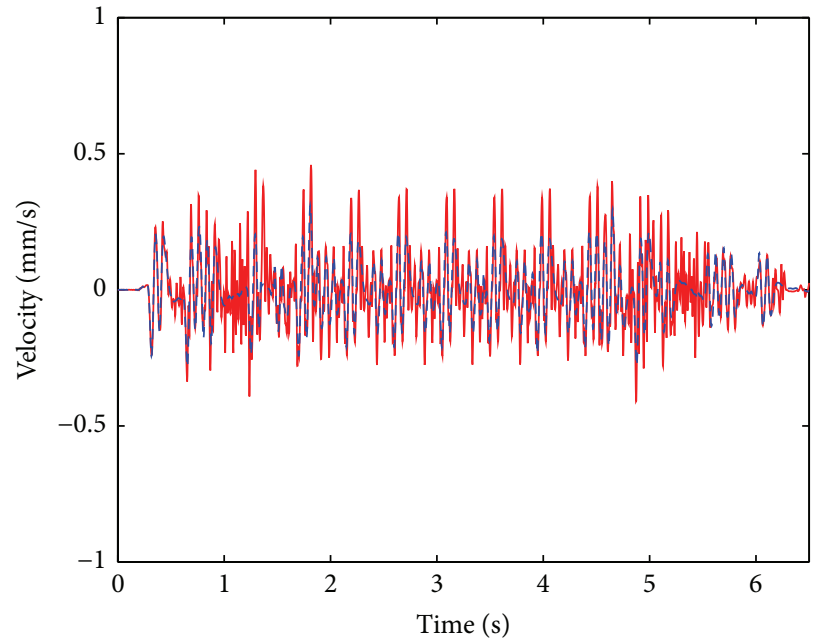

(a) Thalys HST

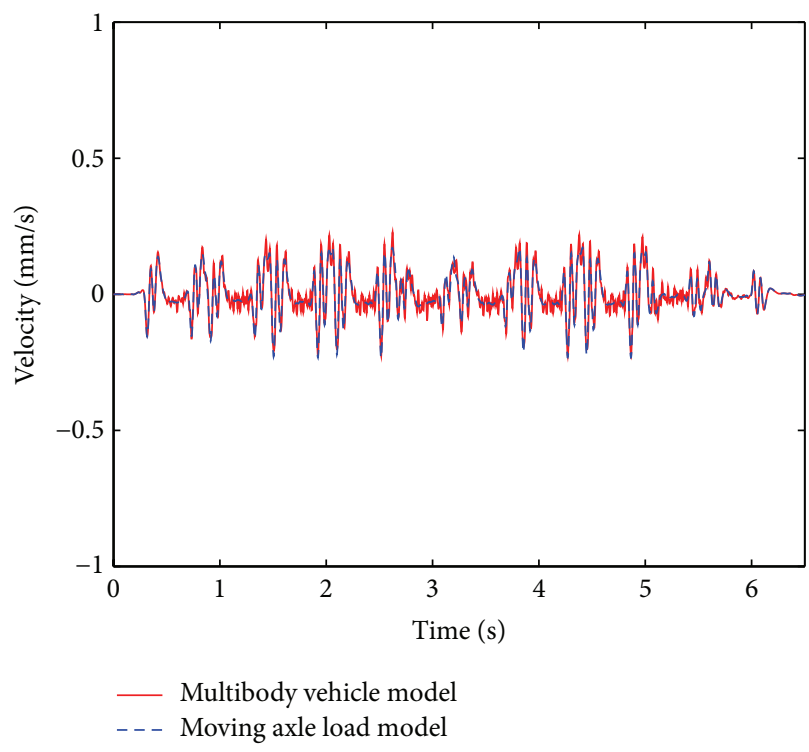

(c) ICE train

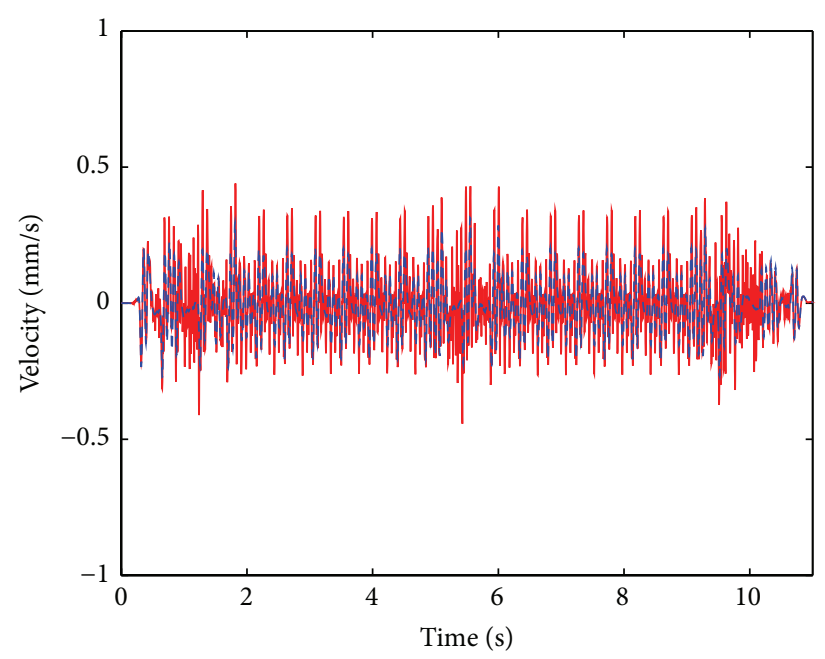

(b) Eurostar HST

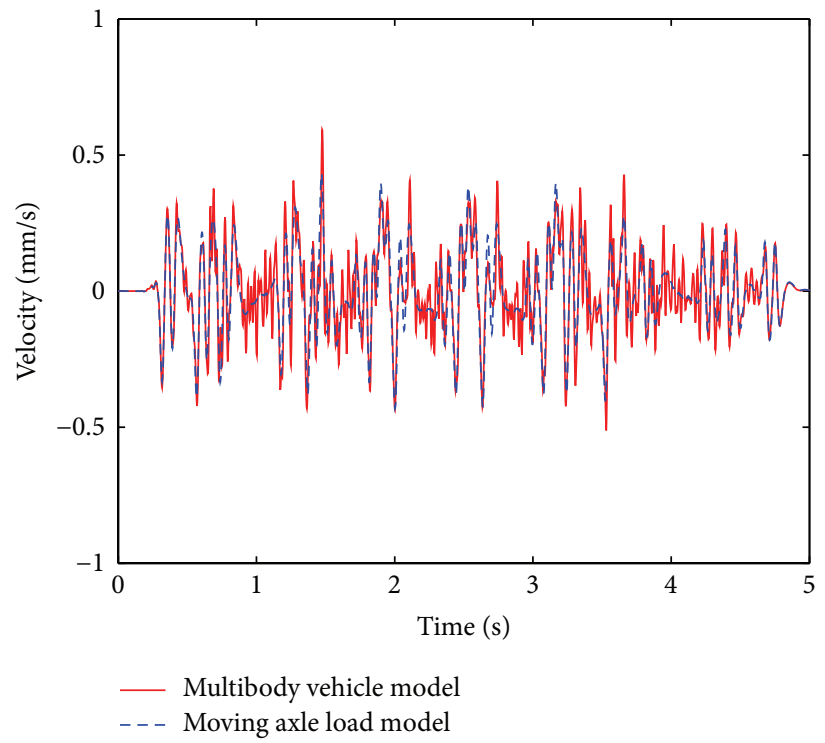

(d) Freight train

FIGURE 9: Time histories of vertical ground surface velocity induced by the studied trains, at $10 \mathrm{~m}$ from the track, for a vehicle speed of $150 \mathrm{~km} / \mathrm{h}$.

level, and shape, according to the geometrical and dynamic configuration of the vehicle. Particularly, the time duration is relatively similar for all vehicles, except for the Eurostar HST, the longest studied rolling stock. Along with results issued from the vehicle multibody model, results related to the simple vehicle models (axle load effects) are also displayed. These are provided by track/soil dynamic analysis where the vehicle is reduced to its axle loads. Notable discrepancies can be observed between the two approaches, with higher levels for the detailed model of the vehicle. Additional high frequency oscillations are obtained by the vehicle multibody approach. The passing of each train wheelset is also readily identified. Figure 9 shows the effect of each load on the ground vibrations regularly spaced.

Figure 10 shows the same results but in frequency domain. A third result is added, related to the multibody model (MBS model) for the case where the vehicle rides on a perfect track. This idealistic situation is defined by cancelling $h(x)$ in (2). It can be seen that the main difference exists at the mid and high frequency ranges. In this range, the rail unevenness plays an important role and is amplified by wheelset/track dynamics. At low frequencies, the gap between the two approaches is less dominant, but not negligible. It is likely that the vehicle and track dynamics contribute significantly to this. As for the track deflection, these plots do not reveal the sleeper passage frequency, theoretically at $69.4 \mathrm{~Hz}$. At this frequency, soil viscousity absorbs a high proportion of vibration energy.

The maximum vibration level is shown in Figure 11 by plotting the peak particle velocity, defined by

$$
\mathrm{PPV}=\max _{t}\left|v_{z}(t)\right|,
$$




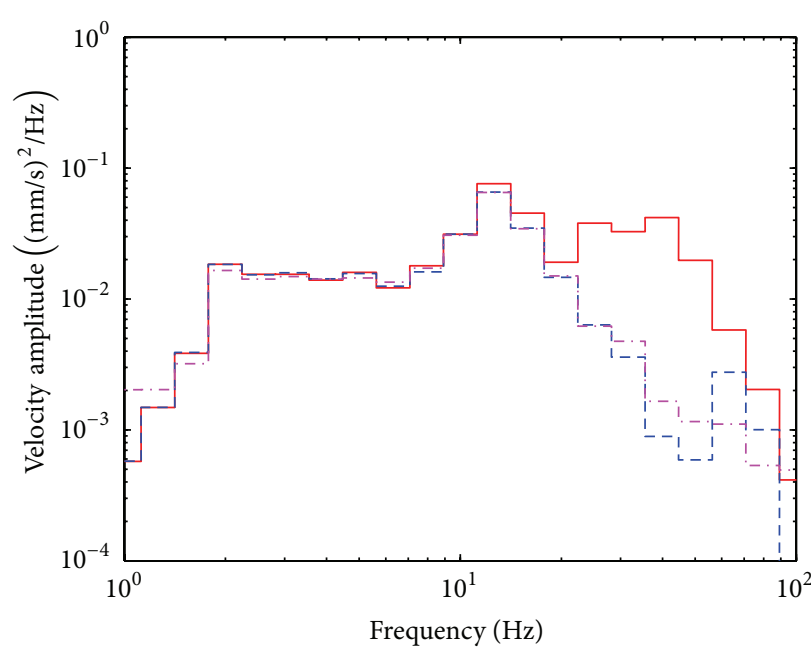

(a) Thalys HST

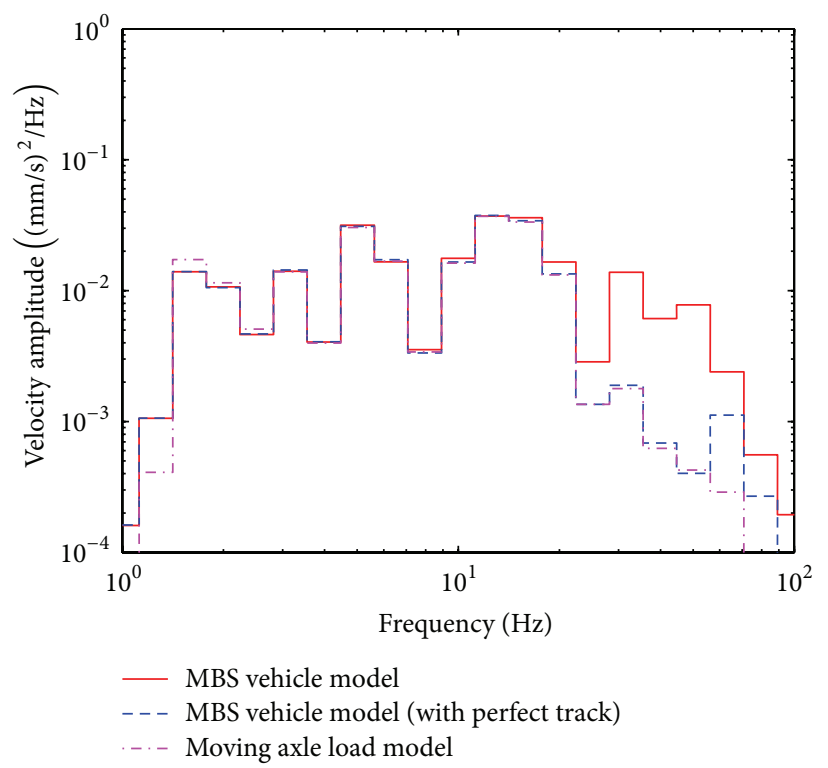

(c) ICE train

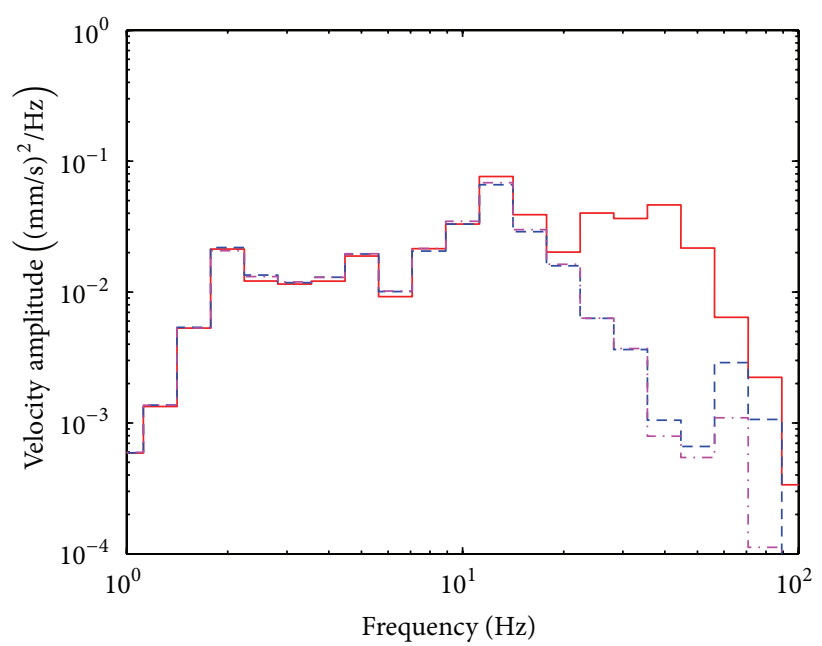

(b) Eurostar HST

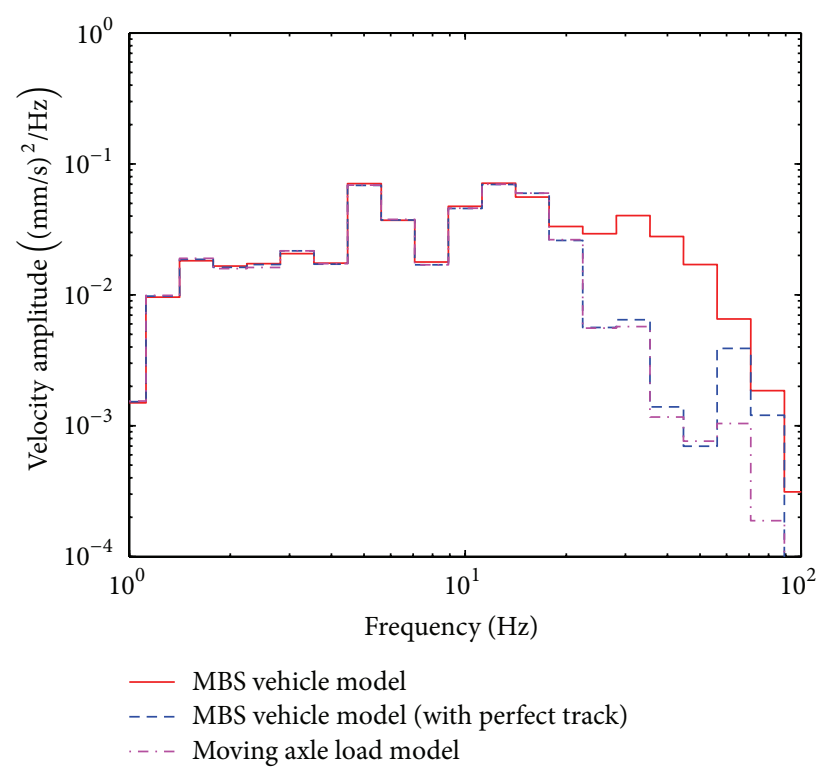

(d) Freight train

FIGURE 10: One-third octave band spectra of vertical ground surface velocity induced by the four studied trains, at $10 \mathrm{~m}$ from the track, for a vehicle speed of $150 \mathrm{~km} / \mathrm{h}$.

as a function of the distance $d$ from the track. This indicator is largely used to evaluate the potential structural damage in buildings [31]. The decrease with the distance is clear and is shown to depend on the vehicle approach (multibody or moving load). The results present large differences over a wide range of distances. For each kind of vehicle, the attenuation can be fitted according to a simple power-law attenuation in the near field

$$
\begin{array}{ll}
\mathrm{PPV} \propto d^{-0.7} & (\text { Thalys HST }), \\
\mathrm{PPV} \propto d^{-0.7} & (\text { Eurostar HST }), \\
\mathrm{PPV} \propto d^{-0.8} & (\text { ICE train }), \\
\mathrm{PPV} \propto d^{-0.5} & \text { (freight train) }
\end{array}
$$

and different from the moving load case where the exponent is close to 0.6 . This strong attenuation of ground vibrations is partially explained by the material and damping of the soil. For a better comparison, Figure 12 presents this indicator divided by the axle load $N$ of the corresponding vehicle. These curves offer another comparison without the influence of the train weight. Effects of the dynamic behaviour and the geometry of the train cause levels to decrease. Although the Eurostar and Thalys HST have similar characteristics, the levels of attenuation caused by the ICE train and the freight train are different: the first one being the most dominant and the second one having a low effect. Interestingly, the simple vehicle model indicates that the ICE vehicle has the most largest PPV/N level while the multibody model indicates the opposite. 


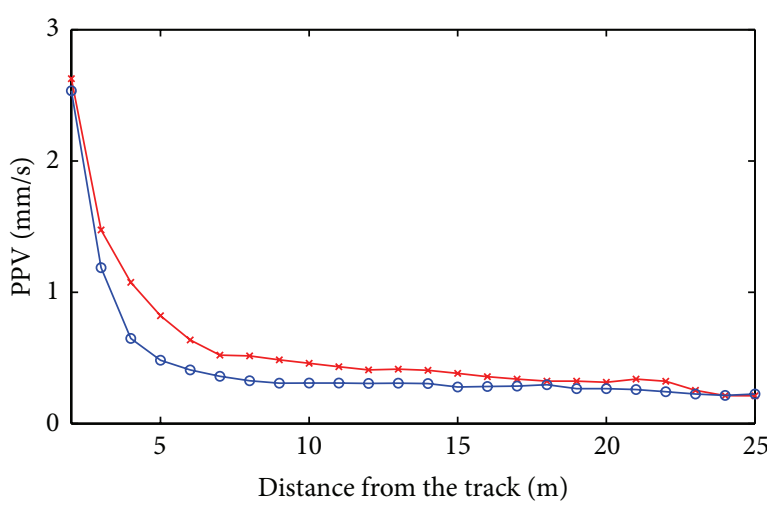

(a) Thalys HST

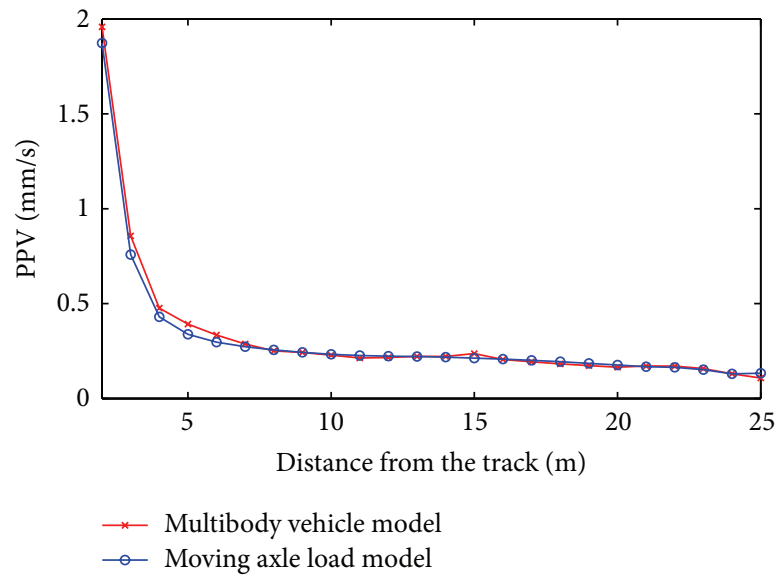

(c) ICE train

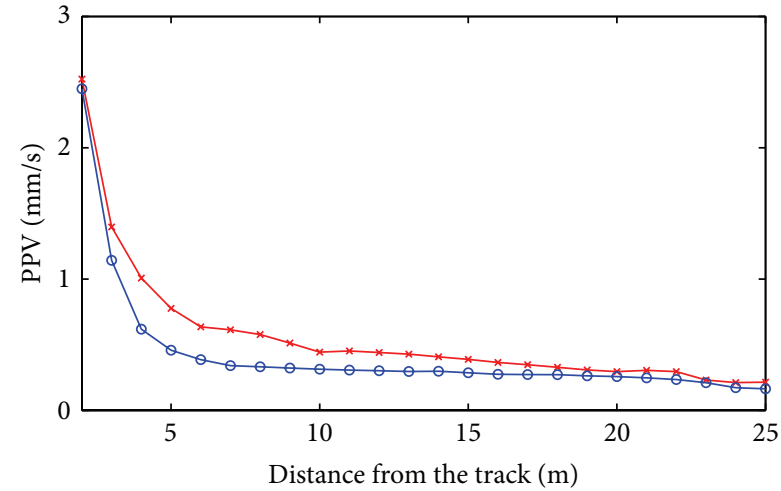

(b) Eurostar HST

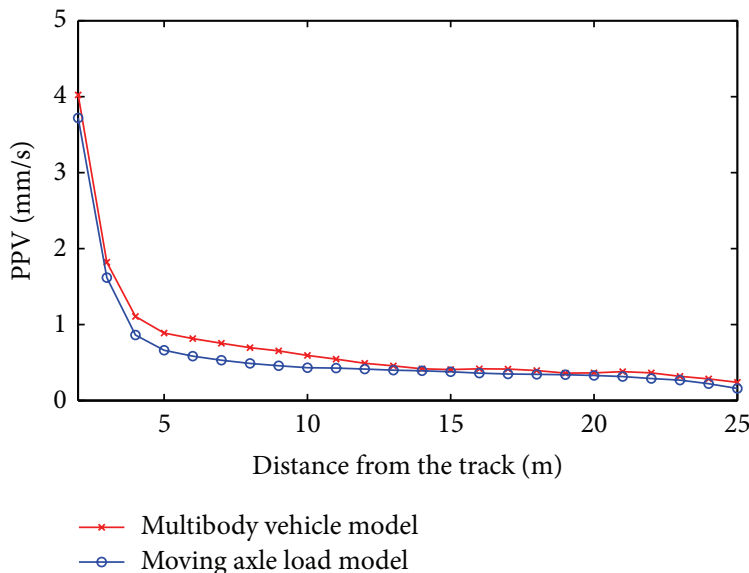

(d) Freight train

FIGURE 11: Influence of the vehicle type on the peak particle velocity, at various distance from the track $\left(v_{0}=150 \mathrm{~km} / \mathrm{h}\right)$.

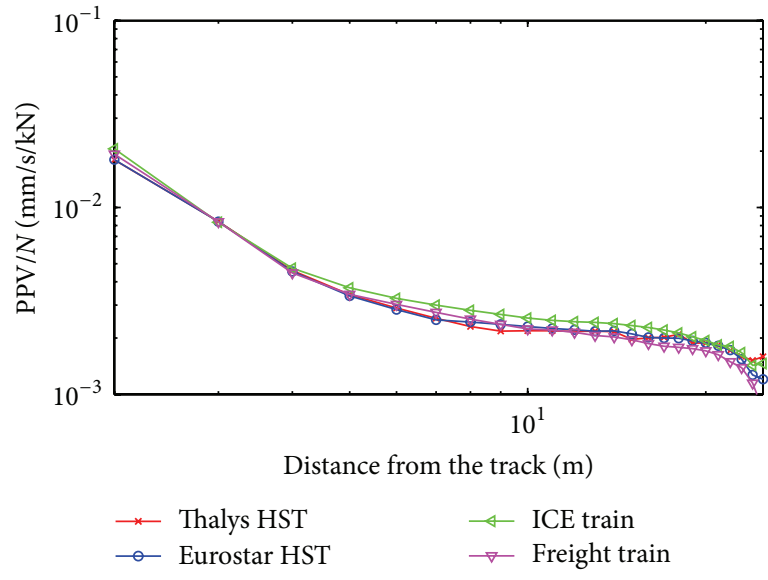

(a) Axle load vehicle model

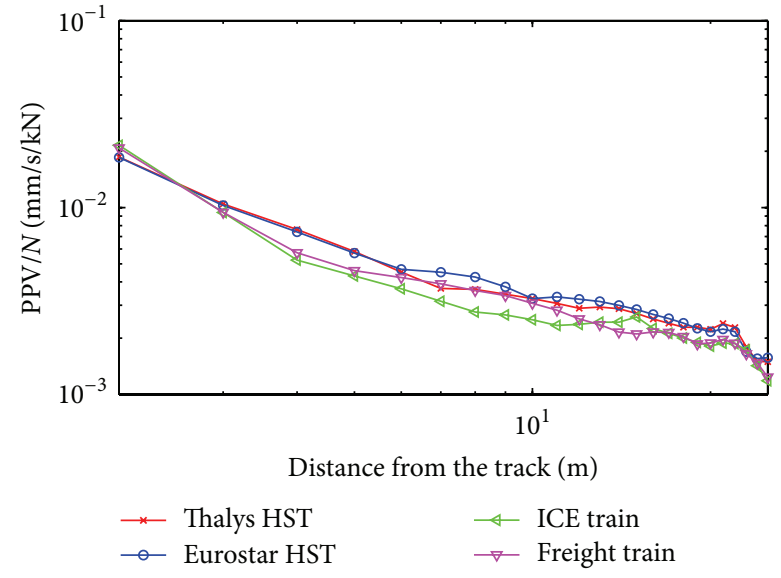

(b) Multibody vehicle model

FIGURE 12: Comparison of PPV/N indicators related to the studied trains for a vehicle speed of $150 \mathrm{~km} / \mathrm{h}$.

As mentioned, vehicle speed is another important parameter. Figure 13 presents the variation of ground vibration level $\mathrm{PPV} / \mathrm{N}$ with $100 \mathrm{~km} / \mathrm{h}$ and $150 \mathrm{~km} / \mathrm{h}$ speeds. The analysis shows the influence of vehicle characteristics on this parameter. The level variation due to speed is not the same for each vehicle. Thalys HST and ICE train present a similar level of $\mathrm{PPV} / \mathrm{N}$ at $100 \mathrm{~km} / \mathrm{h}$ although Thalys HST level is greater at $150 \mathrm{~km} / \mathrm{h}$ (with the Eurostar HST, the level at $150 \mathrm{~km} / \mathrm{h}$ is nearly twice its level at $100 \mathrm{~km} / \mathrm{h}$ ). In addition, the gap widens when moving from 100 to $150 \mathrm{~km} / \mathrm{h}$, with the ICE train representing the vehicle with the smallest effect. 


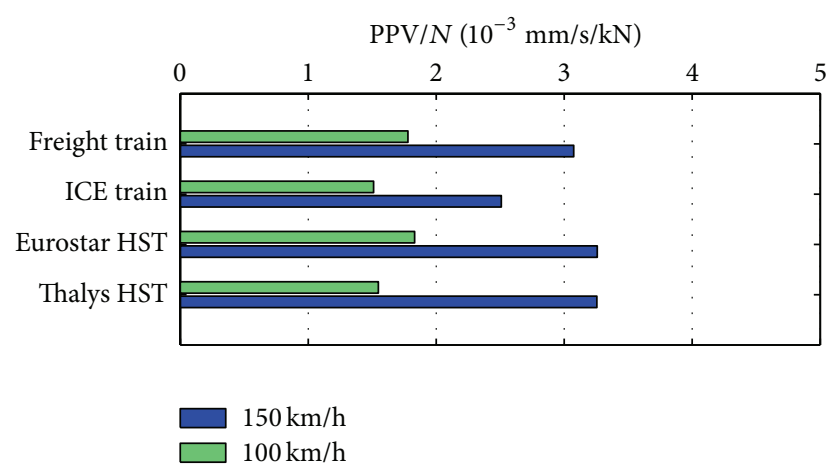

FIGURE 13: Influence of the vehicle speed and the vehicle type on the $\mathrm{PPV} / \mathrm{N}$ indicators at $10 \mathrm{~m}$ from the track.

\section{Conclusions}

Four trains were studied by analysing the ground motion generated by each, in the presence of an identical track/soil configuration. A validated approach is proposed in this work allowing the train and track to be fully coupled. This offers an efficient and robust platform where the rail unevenness or other irregularity on the rail/wheel surface can be accurately modelled. Using numerical simulations it was possible to investigate the parameters affecting both the time domain and frequency spectra.

(i) The geometrical arrangement of train bogies amplifies specific frequencies $\left(f_{a}\right.$ and $\left.f_{b}\right)$ which effects the overall frequency spectrum. The high-speed trains studied (Thalys and Eurostar) use a bogie arrangement for which the modulation is less complex (Jacobs bogie inducing $L_{c}=L_{b}$ ) than the non-high-speed trains studied.

(ii) Axle loads are one of the main parameters affecting ground vibration levels. Therefore, when possible, it is suggested to work with indicators (e.g., PPV) divided by the nominal axle load. This new indicator, independent of the axle load, provides an efficient way to estimate the train dynamic excitation. This allows for the influence of the train on ground motion to be isolated.

(iii) A detailed vehicle model more accurately simulates vibration in the presence track surface irregularity (particularly in the mid frequency range), in comparison to a reduced degree of freedom model. Similar findings were made regarding the effect of changes in train speed. Therefore a detailed vehicle model may be justified for projects where existing standards are restrictive (i.e., where high accuracy predictions are required).

In summary, including vehicle dynamics and track irregularities within railway vibration prediction models can offer elevated prediction performance. Furthermore, it is advantageous for train manufacturers to design their rolling stock with ground vibration in mind.

\section{Conflict of Interests}

The authors declare that there is no conflict of interests regarding the publication of this paper.

\section{References}

[1] A. M. Kaynia, C. Madshus, and P. Zackrisson, "Ground vibration from high-speed trains: prediction and countermeasure," Journal of Geotechnical and Geoenvironmental Engineering, vol. 126, no. 6, pp. 531-537, 2000.

[2] K. E. Vogiatzis, "Athens metro extension project to Piraeus ground borne noise and vibration assessment and control," International Journal of Mechanics, vol. 6, no. 2, pp. 130-139, 2012.

[3] D. P. Connolly, G. Kouroussis, A. Giannopoulos, O. Verlinden, P. K. Woodward, and M. C. Forde, "Assessment of railway vibrations using an efficient scoping model," Soil Dynamics and Earthquake Engineering, vol. 58, pp. 37-47, 2014.

[4] X. Sheng, C. J. C. Jones, and D. J. Thompson, "A theoretical study on the influence of the track on train-induced ground vibration," Journal of Sound and Vibration, vol. 272, no. 3-5, pp. 909-936, 2004.

[5] G. Lombaert, G. Degrande, J. Kogut, and S. François, “The experimental validation of a numerical model for the prediction of railway induced vibrations," Journal of Sound and Vibration, vol. 297, no. 3-5, pp. 512-535, 2006.

[6] P. Galvín and J. Domínguez, "Experimental and numerical analyses of vibrations induced by high-speed trains on the CórdobaMálaga line," Soil Dynamics and Earthquake Engineering, vol. 29, no. 4, pp. 641-657, 2009.

[7] L. Auersch, "Dynamic axle loads on tracks with and without ballast mats: numerical results of three-dimensional vehicletrack-soil models," Proceedings of the Institution of Mechanical Engineers, Part F: Journal of Rail and Rapid Transit, vol. 220, no. 2, pp. 169-183, 2006.

[8] V. V. Krylov, "Generation of ground vibrations by superfast trains," Applied Acoustics, vol. 44, no. 2, pp. 149-164, 1995.

[9] A. V. Metrikine and K. Popp, "Steady-state vibrations of an elastic beam on a visco-elastic layer under moving load," Archive of Applied Mechanics, vol. 70, no. 6, pp. 399-408, 2000.

[10] M. J. Steenbergen and A. V. Metrikine, "The effect of the interface conditions on the dynamic response of a beam on a half-space to a moving load," European Journal of Mechanics: A Solids, vol. 26, no. 1, pp. 33-54, 2007.

[11] M. Shamalta and A. V. Metrikine, "Analytical study of the dynamic response of an embedded railway track to a moving load," Archive of Applied Mechanics, vol. 73, no. 1-2, pp. 131-146, 2003.

[12] F. Lu, Q. Gao, J. H. Lin, and F. W. Williams, "Non-stationary random ground vibration due to loads moving along a railway track," Journal of Sound and Vibration, vol. 298, no. 1-2, pp. 3042, 2006.

[13] G. Lombaert and G. Degrande, "Ground-borne vibration due to static and dynamic axle loads of InterCity and high-speed trains," Journal of Sound and Vibration, vol. 319, no. 3-5, pp. 1036-1066, 2009.

[14] L. Auersch, "Theoretical and experimental excitation force spectra for railway-induced ground vibration: vehicle-tracksoil interaction, irregularities and soil measurements," Vehicle System Dynamics, vol. 48, no. 2, pp. 235-261, 2010. 
[15] V. V. Krylov, "Effect of track properties on ground vibrations generated by high-speed trains," Acustica, vol. 84, no. 1, pp. 7890, 1998.

[16] C. Madshus and A. M. Kaynia, "High-speed railway lines on soft ground: dynamic behaviour at critical train speed," Journal of Sound and Vibration, vol. 231, no. 3, pp. 689-701, 2000.

[17] P. A. Costa, A. Colaço, R. Calçada, and A. S. Cardoso, "Critical speed of railway tracks. Detailed and simplified approaches," Transportation Geotechnics, vol. 2, pp. 30-46, 2015.

[18] X. Sheng, C. J. C. Jones, and D. J. Thompson, "A comparison of a theoretical model for quasi-statically and dynamically induced environmental vibration from trains with measurements," Journal of Sound and Vibration, vol. 267, no. 3, pp. 621-635, 2003.

[19] P. Galvín, A. Romero, and J. Domínguez, "Fully threedimensional analysis of highspeed train-track-soil-structure dynamic interaction," Journal of Sound and Vibration, vol. 329, no. 24, pp. 5147-5163, 2010.

[20] G. Lombaert, P. Galvín, S. François, and G. Degrande, "Quantification of uncertainty in the prediction of railway induced ground vibration due to the use of statistical track unevenness data," Journal of Sound and Vibration, vol. 333, no. 18, pp. 42324253, 2014.

[21] L. Auersch and S. Said, "Attenuation of ground vibrations due to different technical sources," Earthquake Engineering and Engineering Vibration, vol. 9, no. 3, pp. 337-344, 2010.

[22] D. P. Connolly, G. Kouroussis, P. K. Woodward, P. A. Costa, O. Verlinden, and M. C. Forde, "Field testing and analysis of high speed rail vibrations," Soil Dynamics and Earthquake Engineering, vol. 67, pp. 102-118, 2014.

[23] P. A. Costa, R. Calçada, and A. S. Cardoso, "Influence of train dynamic modelling strategy on the prediction of track-ground vibrations induced by railway traffic," Journal of Rail and Rapid Transit, vol. 226, no. 4, pp. 434-450, 2012.

[24] G. Kouroussis, O. Verlinden, and C. Conti, "Efficiency of resilient wheels on the alleviation of railway ground vibrations," Proceedings of the Institution of Mechanical Engineers, Part F: Journal of Rail and Rapid Transit, vol. 226, no. 4, pp. 381-396, 2012.

[25] G. Kouroussis, O. Verlinden, and C. Conti, "Influence of some vehicle and track parameters on the environmental vibrations induced by railway traffic," Vehicle System Dynamics, vol. 50, no. 4, pp. 619-639, 2012.

[26] G. Kouroussis, D. P. Connolly, and O. Verlinden, "Railwayinduced ground vibrations-a review of vehicle effects," International Journal of Rail Transportation, vol. 2, no. 2, pp. 69-110, 2014.

[27] G. Kouroussis, O. Verlinden, and C. Conti, "A two-step time simulation of ground vibrations induced by the railway traffic," Proceedings of the Institution of Mechanical Engineers, Part C: Journal of Mechanical Engineering Science, vol. 226, no. 2, pp. 454-472, 2012.

[28] G. Kouroussis, G. Gazetas, I. Anastasopoulos, C. Conti, and O. Verlinden, "Discrete modeling of vertical track-soil coupling for vehicle-track dynamics," Soil Dynamics and Earthquake Engineering, vol. 31, no. 12, pp. 1711-1723, 2011.

[29] International Organization for Standardization, ISO 2631-2: Mechanical Vibration and Shock-Evaluation of Human Exposure to Whole-Body Vibration-Part 2: Vibration in Buildings (1 to $80 \mathrm{~Hz}$ ), International Organization for Standardization, Geneva, Switzerland, 2003.
[30] Deutsches Institut fur Normung, DIN 4150-2: Structural Vibrations-Part 2: Human Exposure to Vibration in Buildings, Deutsches Institut fur Normung, 1999.

[31] Deutsches Institut fur Normung, DIN 4150-3: Structural Vibrations_Part 3: Effects of Vibration on Structures, 1999.

[32] M. Hiller, "Dynamics of multibody system with minimal coordinates," in Proceedings of the NATO Advanced Study Institute on Computer-Aided Analysis of Rigid and Flexible Mechanical Systems, M. F. O. Pereira and J. C. Ambrosio, Eds., pp. 119-163, Tróia, Portugal, 1993.

[33] S. L. Grassie, R. W. Gregory, D. Harrison, and K. L. Johnson, "The dynamic response of railway track to high frequency vertical excitation," Journal of Mechanical Engineering Science, vol. 24, no. 2, pp. 77-90, 1982.

[34] K. L. Knothe and S. L. Grassie, "Modelling of railway track and vehicle/track interaction at high frequencies," Vehicle System Dynamics, vol. 22, no. 3-4, pp. 209-262, 1993.

[35] V. K. Garg and R. V. Dukkipati, Dynamics of Railway Vehicle Systems, Academic Press, Toronto, Canada, 1984.

[36] O. Verlinden, L. B. Fékih, and G. Kouroussis, "Symbolic generation of the kinematics of multibody systems in EasyDyn: from MuPAD to Xcas/Giac," Theoretical and Applied Mechanics Letters, vol. 3, no. 1, Article ID 013012, 2013.

[37] G. Kouroussis, L. Van Parys, C. Conti, and O. Verlinden, "Using three-dimensional finite element analysis in time domain to model railway-induced ground vibrations," Advances in Engineering Software, vol. 70, pp. 63-76, 2014.

[38] G. Kouroussis, O. Verlinden, and C. Conti, "Ground propagation of vibrations from railway vehicles using a finite/infiniteelement model of the soil," Journal of Rail and Rapid Transit, vol. 223, no. 4, pp. 405-413, 2009.

[39] J. Kim, Y. H. Kang, H.-H. Choi, S.-M. Hwang, and B. S. Kang, "Comparison of implicit and explicit finite-element methods for the hydroforming process of an automobile lower arm," The International Journal of Advanced Manufacturing Technology, vol. 20, no. 6, pp. 407-413, 2002. 

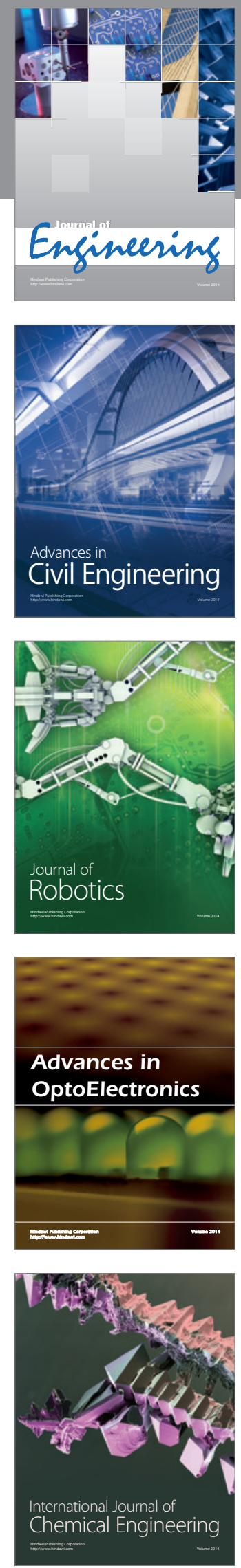

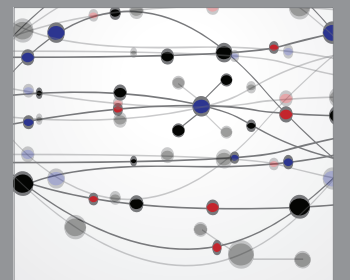

The Scientific World Journal
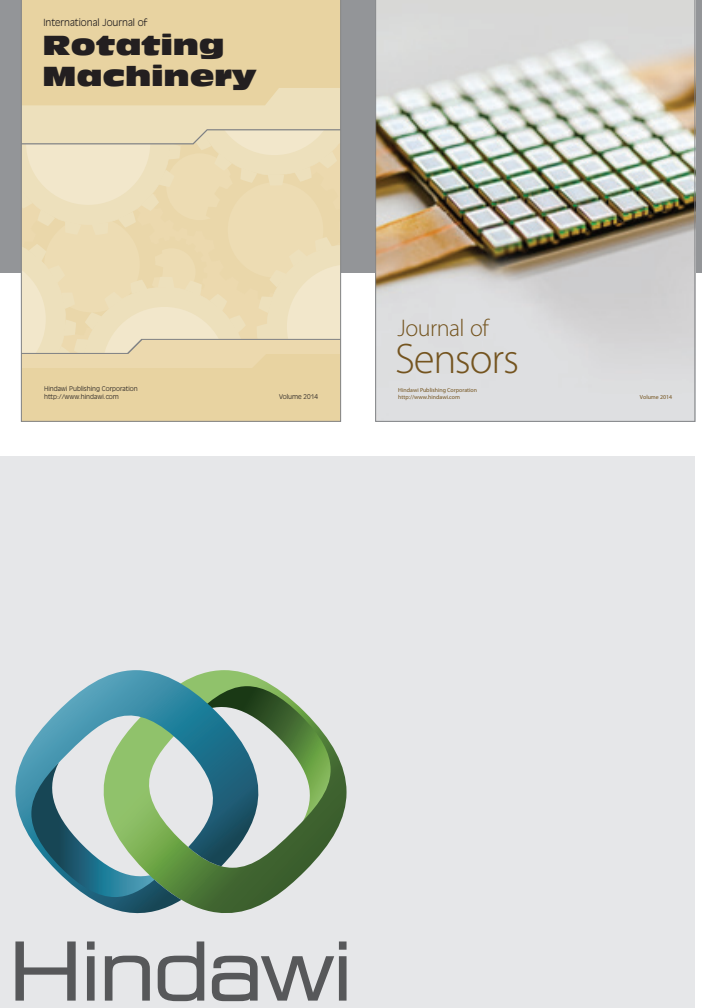

Submit your manuscripts at http://www.hindawi.com
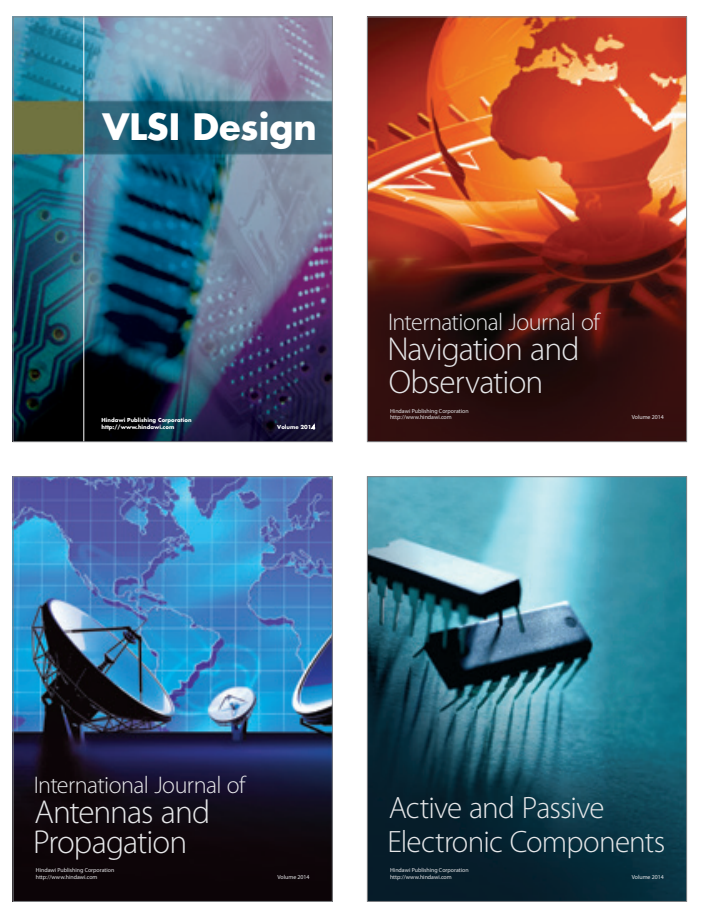
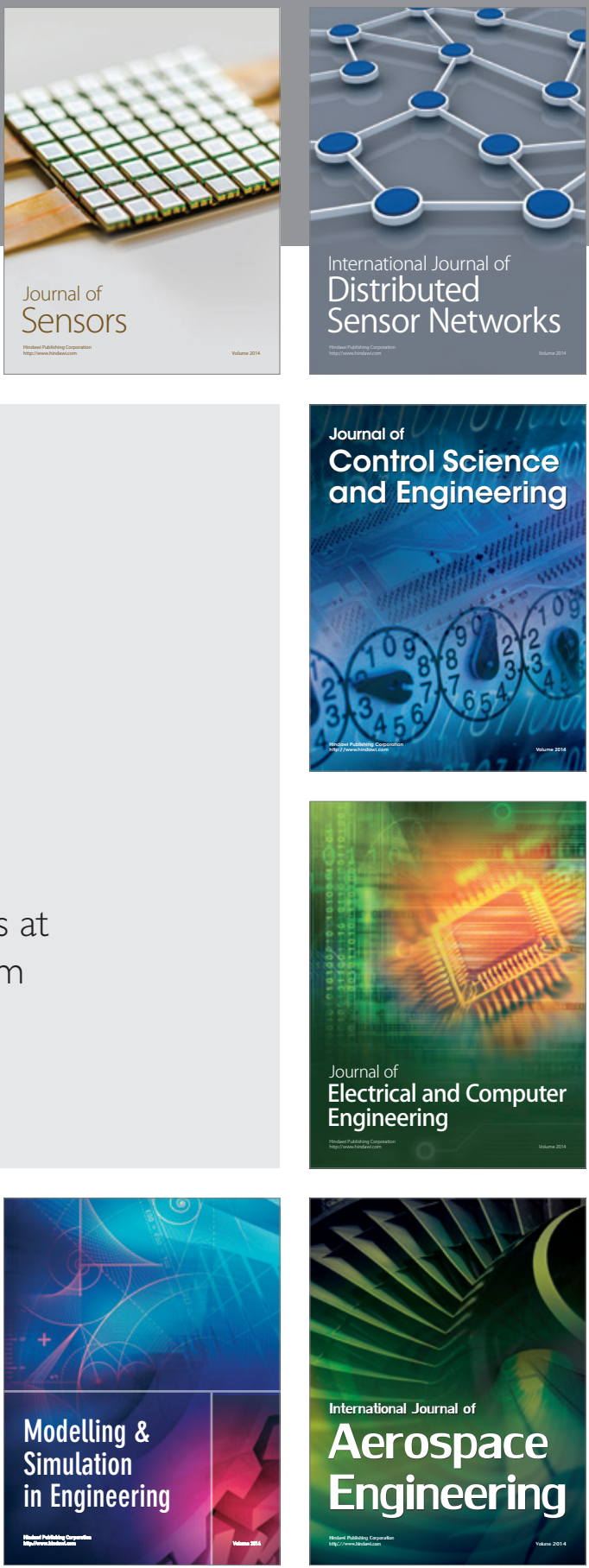

Journal of

Control Science

and Engineering
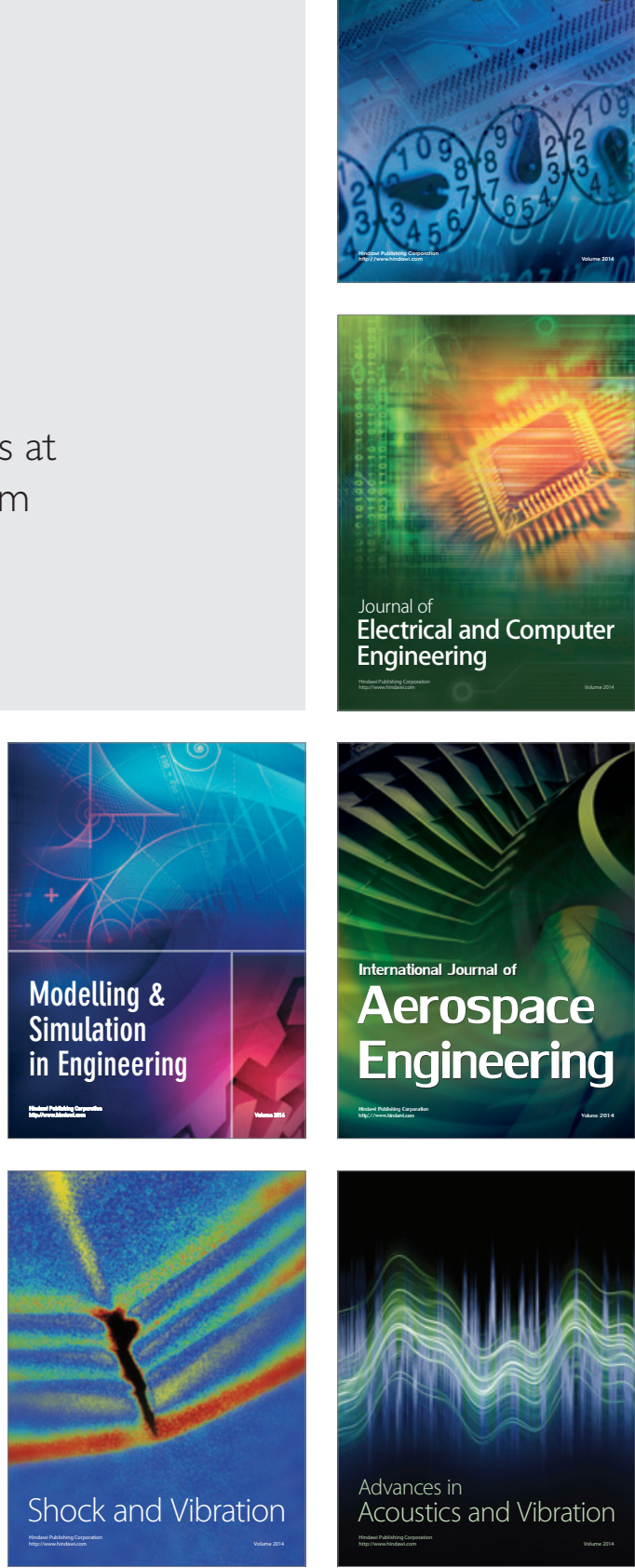